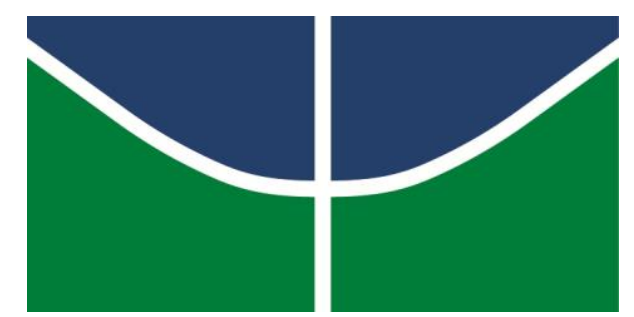

Universidade de Brasília

Instituto de Ciências Biológicas

Programa de Pós-Graduação em Zoologia

\title{
Morfometria alar das espécies do subgênero \\ Lutzomyia (Diptera, Psychodidae, Phlebotominae) que ocorrem no Brasil
}

Bárbara Giordani Fagundes 


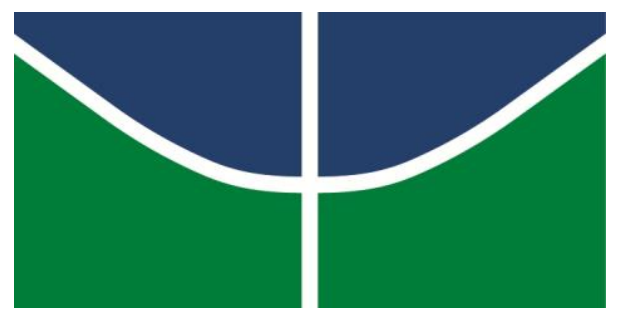

Universidade de Brasília

Instituto de Ciências Biológicas

Programa de Pós-Graduação em Zoologia

\section{Morfometria alar das espécies do subgênero \\ Lutzomyia (Diptera, Psychodidae, Phlebotominae) que ocorrem no Brasil}

Bárbara Giordani Fagundes

Dissertação apresentada ao Programa de PósGraduação em Zoologia como um dos requisitos para obtenção do título de Mestre em Zoologia.

Orientador: Prof. Dr. Rodrigo Gurgel Gonçalves 


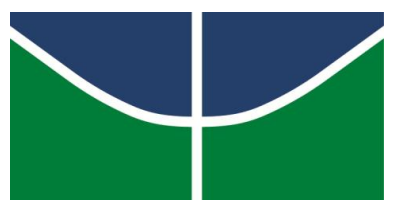

Universidade de Brasília Instituto de Ciências Biológicas

Programa de Pós-Graduação em Zoologia

Dissertação de Mestrado

\section{BÁRBARA GIORDANI FAGUNDES}

Título:

Morfometria alar das espécies do subgênero Lutzomyia (Diptera, Psychodidae, Phlebotominae) que ocorrem no Brasil

\section{Banca Examinadora:}

Prof. Dr. Rodrigo Gurgel Gonçalves

Presidente/Orientador

FM/UnB

Prof. Dr. Paulo César Motta

Membro Titular

IB/UnB
Prof. Dr. Marcos Takashi Obara

Membro Titular

FCE/UnB

Profa. Dra. Marina Regina Frizzas

Membro suplente

IB/UnB

Brasília, 29 de julho de 2016. 


\section{AGRADECIMENTOS}

Ao meu orientador Prof. Dr. Rodrigo Gurgel Gonçalves, pela paciência, conselhos, companheirismo e, principalmente, compreensão. Mesmo com todas as adversidades ocorridas ao longo do mestrado, sempre me incentivou e apoiou nos momentos mais difíceis. Admiro muito o profissional e a pessoa que você é.

Ao Prof. Dr. Andrey José de Andrade, da Universidade Federal do Paraná, que não foi só um colaborador, na verdade, foi uma peça fundamental para conclusão dessa dissertação, não só pelas sugestões e revisões desse trabalho, mas também pelo imenso apoio, incentivo, dedicação e, mesmo longe, não deixou de me ajudar. Você é uma pessoa iluminada e que sempre conquistará a todos por onde passar. Não esquecerei o tempo e a atenção que dedicou a mim nessa trajetória.

À Profa. Dra. Eunice Aparecida Bianchi Galati, pelas valiosas ideias e suporte dados a mim nesse projeto e por permitir acesso à Coleção Entomológica do Laboratório de Entomologia em Saúde Pública da Universidade de São Paulo (FSP-USP-LESP-Phlebotominae). Agradeço também a Márcia Bicudo, por separar e organizar o material da coleção utilizado para essa pesquisa, e a todos do laboratório por me acolherem ajudando no que necessitei.

À Dra. Paloma Helena Fernandes Shimabukuro, por permitir acesso à Coleção de Flebotomíneos do Centro de Pesquisas René Rachou, Minas Gerais (FIOCRUZ-COLFLEB) oferecendo todo suporte e ajuda que precisei. Agradeço também a todos de seu laboratório que foram muito atenciosos e prestativos.

Aos membros da banca: Dr. Paulo César Motta, Dr. Marcos Takashi Obara e Dra. Marina Regina Frizzas; agradeço por aceitarem o convite e pela compreensão em relação aos prazos;

À Universidade de Brasília (UnB), em especial ao Departamento de Pós-Graduação em Zoologia pela oportunidade de realização do mestrado.

À Profa. Cláudia Pinto e toda equipe gestora da escola em que trabalho (CEF $01 \mathrm{NB}$ ), pela compressão com os meus horários e correria constante, me apoiando principalmente nessa difícil reta final.

Aos meus amigos, André e todos aqueles que me incentivaram e confiram no meu trabalho. 
À minha maravilhosa família que sempre me dá apoio incondicional em tudo que me proponho a fazer. Em especial, a minha mãe Silvana, que não mediu esforços para ajudar de todas as formas possíveis incluindo as tarefas domésticas, os passeios com a Nina e até ajudando nas correções das provas dos meus alunos. Sem você, não teria conseguido. Agradeço também a minha irmã Brenda, por ouvir meus desabafos, ser a minha maior companheira e contribuir com o que pôde para o meu trabalho.

Finalmente, agradeço a Deus por ter restaurado minha saúde e me dado forças para concluir essa importante etapa da minha vida.

Muito obrigada!

Bárbara Giordani Fagundes 
"Lute com determinação, abrace a vida com paixão, perca com classe e vença com ousadia, porque o mundo pertence a quem se atreve e a vida é muito para ser insignificante."

Charles Chaplin 


\section{SUMÁRIO}

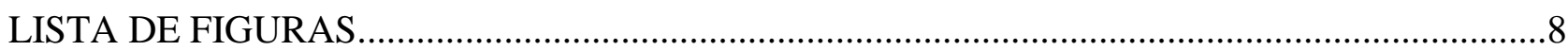

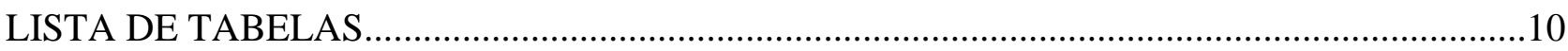

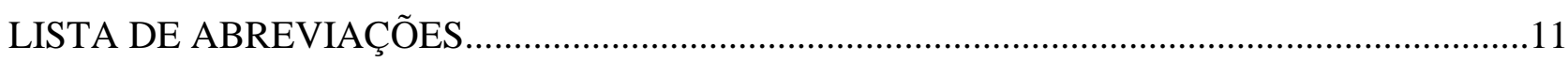

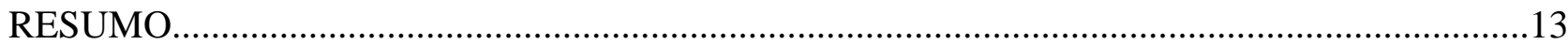

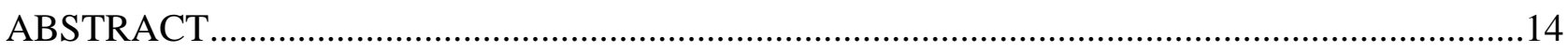

1. INTRODUÇÃO

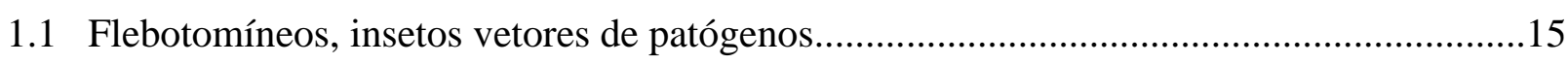

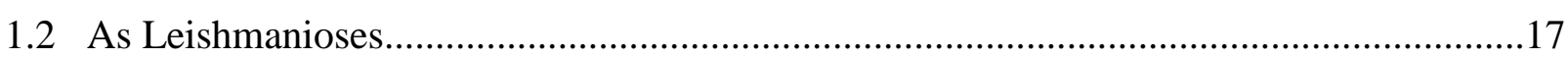

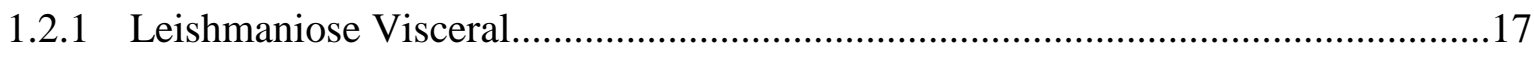

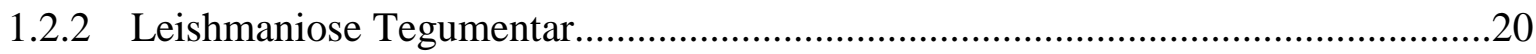

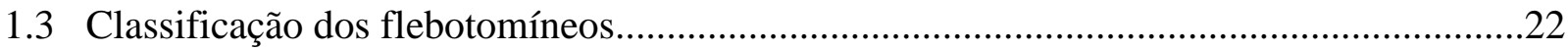

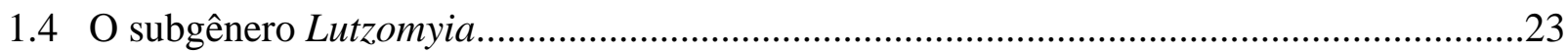

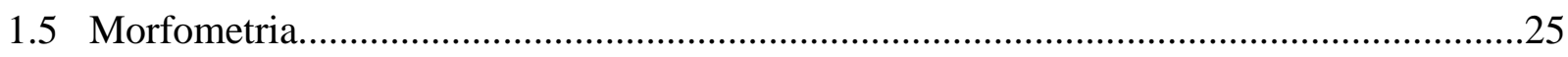

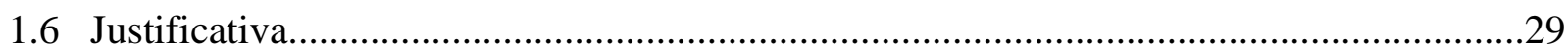

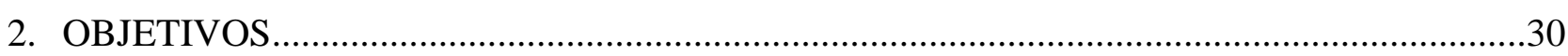

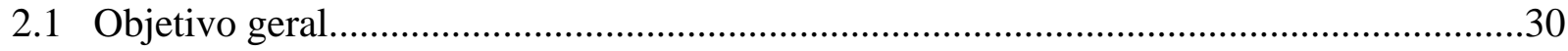

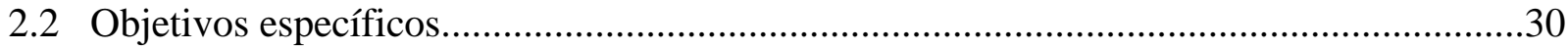

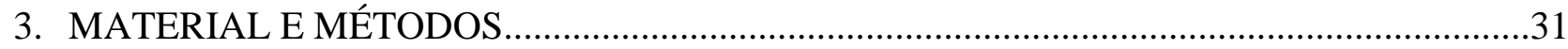

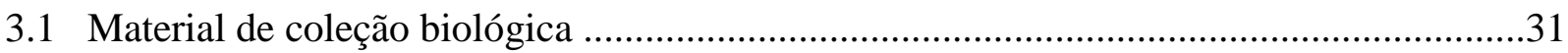

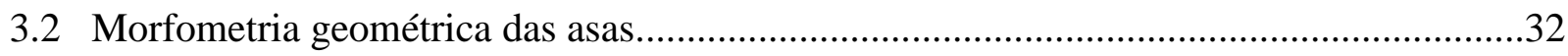

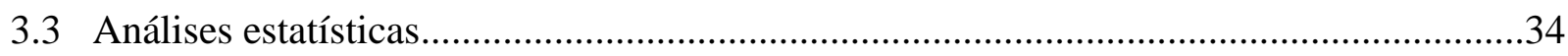

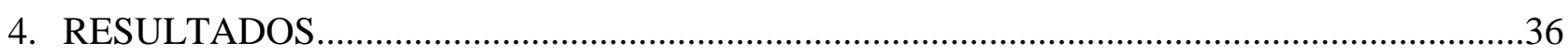

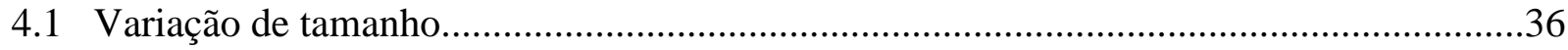

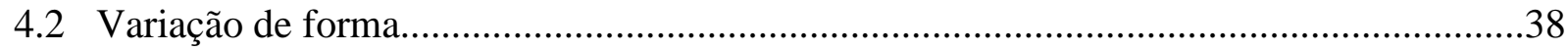

5. DISCUSSÃO

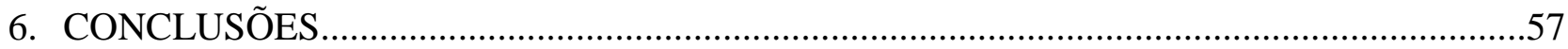

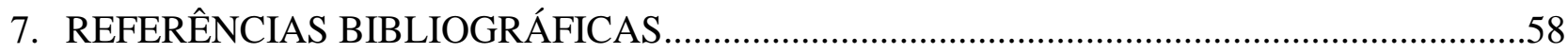

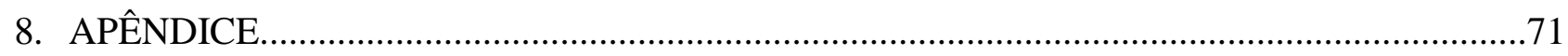




\section{LISTA DE FIGURAS}

Figura 1. Fêmea de Lutzomyia (Lutzomyia) longipalpis realizando repasto sanguíneo (Crédito da imagem: Ray Wilson, Liverpool School of Tropical Medicine). 15

Figura 2. Em “A” e "B” manifestações clínicas de Leishmaniose Visceral acometendo crianças. As áreas marcadas indicam fígado e baço inflamados (Fonte: Brasil, 2006). 18

Figura 3. Manifestações clínicas de Leishmaniose Tegumentar. Em “A” lesão cutânea localizada no punho e em "B” lesão cutânea múltipla localizada no braço (Fonte: Brasil, 2007).

Figura 4. Marcos anatômicos utilizados para análise da morfometria geométrica das asas das espécies de flebotomíneos. Asa de Lutzomyia longipalpis mostrando as veias (R1-5 e M1-4). O polígono vermelho inclui os 6 marcos anatômicos utilizados nas análises com todas as espécies e os pontos em azul indicam os 4 marcos adicionais utilizados nas análises com o grupo de espécies com fêmeas indistinguíveis.

Figura 5. Box-plot mostrando a variação no tamanho do centróide das asas das espécies fotografadas na Universidade de São Paulo. A análise foi feita para fêmeas e machos mostrando a média e desvios-padrão para cada espécie. LAM, Lu. almerioi; LCAV, Lu. cavernicola; LCRU, Lu. cruzi; LDIS, Lu. dispar; LFOR, Lu. forattinii; LGAM, Lu. gaminarai; LLON, Lu. longipalpis......36

Figura 6. Box-plot mostrando a variação no tamanho do centróide das asas das espécies fotografadas na FIOCRUZ. A análise foi feita para fêmeas e machos mostrando a média e desviospadrão para cada espécie. BAVE, Br. avellari; BBRU, Br. brumpti; LALE, Lu. alencari; LAYA, Lu. ayacuchensis; LBAT, Lu. battistinii; LCHN, Lu. ischnacantha; LCHY, Lu. ischyracantha; LLIC, Lu. lichyi; LREN, Lu. renei; LTEJ, Lu. tejadai; MQUI, Mi. quinquefer.

Figura 7. Análise dos componentes principais que apresentaram maior variação. Gráfico mostra a distribuição dos gêneros e dos subgêneros de Lutzomyia pesquisados quando analisados PC1 e PC2. As modificações nas formas das asas estão representadas por A (valores positivos) e B (valores negativos) para PC1 e C (valores positivos) e D (valores negativos) para PC2.

Figura 8. Mapas fatoriais baseados nos dois fatores discriminantes da variação de forma de asas (CV1 e CV2), mostrando os agrupamentos formados em "A" para as fêmeas e em "B" para os machos. Os polígonos foram traçados para facilitar a visualização dos grupos. .40 
Figura 9. Mapas fatoriais baseados nos dois fatores discriminantes da variação de forma de asas (CV1 e CV2), mostrando os agrupamentos formados para as fêmeas e machos do Grupo 1 do subgênero Lutzomyia. Os polígonos foram traçados para facilitar a visualização dos grupos.

Figura 10. Mapas fatoriais baseados nos dois fatores discriminantes da variação de forma de asas (CV1 e CV2), mostrando os agrupamentos formados para as fêmeas e machos do Grupo 2 do subgênero Lutzomyia. Os polígonos foram traçados para facilitar a visualização dos grupos.

Figura 11. Mapas fatoriais baseados nos dois fatores discriminantes da variação de forma de asas (CV1 e CV2), mostrando os agrupamentos formados para as fêmeas e machos do Grupo 2 do subgênero Lutzomyia, considerando 10 marcos anatômicos. Os polígonos foram traçados para facilitar a visualização dos grupos

Figura 12. Mapas fatoriais baseados nos dois fatores discriminantes da variação de forma de asas (CV1 e CV2), mostrando os agrupamentos formados pelas espécies do subgênero Helcocyrtomyia incluindo $\mathrm{Lu}$. forattinii para fêmeas e machos. Os polígonos foram traçados para facilitar a visualização dos grupos.

Figura 13. Em "A" dendrograma baseado na proposta publicada por Galati (2003) e em "B" dendrograma baseado na morfometria geométrica de asas com as características de machos do subgênero Lutzomyia elaborado pelo método de UPGMA (Unweighted Pair-Group Method with Aritmetic Average) derivado das distâncias de Mahalanobis calculadas a partir das variáveis de forma.

Figura 14. Em "A" dendrograma baseado na proposta publicada por Galati (2003) e em "B" dendrograma baseado na morfometria geométrica de asas com as características de fêmeas do subgênero Lutzomyia elaborado pelo método de UPGMA (Unweighted Pair-Group Method with Aritmetic Average) derivado das distâncias de Mahalanobis calculadas a partir das variáveis de forma. .50 


\section{LISTA DE TABELAS}

Tabela 1. Prováveis ciclos de transmissão das leishmanioses encontradas no Brasil. Adaptado de WHO, 2010a

Tabela 2. Lista das espécies analisadas no trabalho com número de fêmeas e machos utilizados, localidade de origem e a coleção de procedência.

Tabela 3. Média do tamanho do centróide para machos e fêmeas de cada uma das espécies analisadas separadas pela coleção de origem.

Tabela 4. Porcentagem de reclassificações corretas das espécies do subgênero Lutzomyia do Grupo 1 após a análise de discriminante com as variáveis de forma.

Tabela 5. Porcentagem de reclassificações corretas das espécies do subgênero Lutzomyia do Grupo 2 após a análise de discriminante com as variáveis de forma

Tabela 6. Porcentagem de reclassificações corretas das espécies do gênero Brumptomyia após a análise de discriminante com as variáveis de forma. 


\section{LISTA DE ABREVIAÇÕES}

ACP - Análise de Componentes Principais

AFD - Análise de Funções Discriminantes

AGP - Análise Generalizada de Procrustes

ANOVA - Análise de Variância

BAVE - Br. avellari

BBRU - Br. brumpti

Br. - Brumptomyia

CV - Variável Canônica

FIOCRUZ - COLFLEB - Coleção de Flebotomíneos do Centro de Pesquisas René Rachou de Minas Gerais

FSP - USP - LESP - Coleção Entomológica do Laboratório de Entomologia em Saúde Pública em Saúde Pública da Universidade de São Paulo

L. - Leishmania

L. (L.) - Leishmania (Leishmania)

L. (V.) - Leishmania (Viannia)

LAD - Leishmaniose Anérgica Difusa

LALE - Lu. alencari

LAM - Lu. almerioi

LAYA - Lu. ayacuchensis

LBAT - Lu. battistinii

LCAV - Lu. cavernicola

LCHN - Lu. ischnacantha

LCHY - Lu. ischyracantha

LCRU - Lu. cruzi

LDIS - Lu. dispar

LFOR - Lu. forattinii

LGAM - Lu. gaminarai

LLIC - Lu. lichyi 
LLON - Lu. longipalpis

LMC - Leishmaniose Mucocutânea

LREN - Lu. renei

LT - Leishmaniose Tegumentar

LTA - Leishmaniose Tegumentar Americana

LTEJ - Lu. tejadai

Lu. - Lutzomyia

LV - Leishmaniose Visceral

Mi. - Micropygomyia

MQUI - Mi. quinquefer

OMS - Organização Mundial de Saúde

Pa. - Psathyromyia

PC - Componente Principal

Ph. - Phlebotomus

Pi. - Pintomyia

Ps. - Psychodopygus

TC - Tamanho do Centróide 


\section{RESUMO}

Phlebotominae (Dipetra: Psychodidae) é uma subfamília de insetos de grande importância em Saúde Pública por serem transmissores de espécies de Leishmania. O subgênero Lutzomyia merece uma atenção especial por conter a principal espécie vetora de Leishmania infantum, causadora de Leishmaniose Visceral nas Américas: Lutzomyia longipalpis. Esse subgênero possui um grupo de espécies crípticas que não podem ser diferenciadas por morfologia. No entanto, a identificação correta dessas espécies tem relevantes implicações epidemiológicas. Logo, a busca de mais caracteres taxonômicos e métodos para identificação torna-se fundamental e, nesse sentido, a morfometria geométrica de asas poderia auxiliar como uma técnica importante. O objetivo do presente estudo foi analisar as variações de forma e tamanho de asas das espécies do subgênero Lutzomyia que ocorrem no Brasil e avaliar se essas análises poderiam ser úteis para a separação dessas espécies. Foram analisadas asas de 18 espécies de flebotomíneos depositadas na Coleção da Faculdade de Saúde Pública da Universidade de São Paulo e na Coleção do Centro de Pesquisas René Rachou, FIOCRUZ, Minas Gerais, pertencentes ao subgênero Lutzomyia. Outros gêneros e subgêneros foram utilizados como grupo externo. As asas foram fotografadas e seis marcos anatômicos foram digitalizados para obtenção das coordenadas cartesianas. Por meio da Análise Generalizada de Procrustes foi possível obter as variáveis de tamanho e forma. Análises de Componentes Principais, de Funções Discriminantes e de Análise de Variância foram realizadas para analisar as modificações na forma e tamanho das asas. Ainda foi utilizada uma análise baseada nas distâncias de Mahalanobis para verificar os agrupamentos formados por geometria alar. Os resultados obtidos mostraram significativa variação de tamanho e forma das asas de Lutzomyia (Lutzomyia) em comparação com outros subgêneros e gêneros de flebotomíneos. Considerando somente o subgênero Lutzomyia a morfometria alar diferenciou dois grupos. Um deles formado por Lu. ischnacantha, Lu. cavernicola, Lu. almerioi, Lu. forattinii, Lu. renei e Lu. battistinii no qual os valores de reclassificação correta das espécies foram muito altos (Kappa =0,91) e o outro incluindo Lu. alencari, Lu. ischyracantha, Lu. cruzi, Lu. longipalpis, Lu. gaminarai e Lu. lichyi em que esses valores foram baixos (Kappa $=0,42)$, mesmo utilizando 10 marcos anatômicos das asas. Os agrupamentos gerados pela geometria das asas reforçaram a proposta de classificação de Galati (2003). A morfometria geométrica de asas foi útil para identificar padrões morfológicos de gêneros e subgêneros e auxiliar na identificação de algumas espécies de flebotomíneos do subgênero Lutzomyia, mas não permitiu a identificação de espécies crípticas como L. longipalpis and L.cruzi.

Palavras-Chave: Phlebotominae, geometria alar, complexo Lu. longipalpis, espécies crípticas. 


\section{ABSTRACT}

Phlebotominae (Diptera: Phlebotominae) is a subfamily of insects with great importance for Public Health as transmitters of Leishmania species. The Lutzomyia subgenus deserves special attention because contains the main vector species of Leishmania infantum, responsible for Visceral Leishmaniasis in the Americas: Lutzomyia longipalpis. This subgenus includes a group of sibling species that are not differentiated by morphology. However, the correct identification of these species has important epidemiological implications. Thus, the search for more taxonomic characters and methods for identification is fundamental and, in this sense, the wing geometry can help as an important tool. The objective of this study was to analyze the variations in size and shape of wings of Lutzomyia subgenus species occurring in Brazil and assess whether these analyzes can be useful to identify these species. Wings of 18 sand fly species from two Brazilian collections (Collection of the School of Public Health - University of São Paulo and Collection of the Research Center René Rachou - FIOCRUZ, MG) were analyzed. Other genera and subgenera were used as outgroups. The wings were photographed and six landmarks were scanned to obtain the cartesian coordinates. A Generalized Procrustes Analysis was performed to obtain variables of size and shape. Principal Component Analysis, Discriminant Functions and Variance Analysis were performed to analyze the changes in the shape and size of the wings. An analysis with the Mahalanobis distances was also performed to check the groups formed by wing geometry. The results showed significant variation in size and shape of species of Lutzomyia (Lutzomyia) wings when compared to other sandflies subgenera and genera. Considering only the Lutzomyia subgenus, the wing morphometry distinguished two groups. In the group 1 (Lu. ischnacantha, Lu. cavernicola, Lu. almerioi, Lu. forattinii, Lu. renei and $\mathrm{Lu}$. battistinii) correct reclassification scores were very high (Kappa = 0.91), but in the group 2 (Lu. alencari, Lu. ischyracantha, Lu. cruzi, Lu. longipalpis, Lu. gaminarai and $L u$. lichyi) lower reclassification scores were observed (Kappa $=0.42$ ) even in analyses using ten wing landmarks. The clusters generated by wing morphometry were similar of those proposed by Galati (2003).The wing geometry proved to be useful to identify morphological patterns of Phlebotominae genera and subgenera and assist in the identification of some species of the Lutzomyia subgenus but the technique did not allow identification of sibling species such as $L$. longipalpis and L.cruzi.

Keywords: Phlebotominae, wing geometry, Lu. longipalpis complex, sibling species. 


\section{INTRODUÇÃO}

\subsection{Flebotomíneos, insetos vetores de patógenos}

Os flebotomíneos são dípteros pertencentes à família Psychodidae e à subfamília Phlebotominae. Popularmente, são conhecidos como "mosquito palha", "asa dura" ou "birigui" entre outros nomes comuns. Apresentam pequeno porte (medindo de 2 a $3 \mathrm{~mm}$ de comprimento) e cor que pode variar de castanho claro a escuro com corpo coberto por um grande número de cerdas, dando-lhes um aspecto "piloso" (Killick-Kendrick,1999) (Figura 1). São holometábolos, passando pelas fases de ovo, quatro estádios larvais, pupa e adulto. Cada estádio pode ter duração variável de acordo com a espécie, condições climáticas e alimentação. Distinguem-se dos demais insetos de sua família por possuírem um corpo mais delgado, pernas mais longas e finas, além de suas fêmeas precisarem de uma dieta sanguínea. Possuem asas lanceoladas, estreitas, hialinas e densamente revestidas de cerdas longas. Essas, quando em repouso, permanecem eretas e fletidas para cima (Brazil \& Brazil, 2003; Sherlock, 2003).

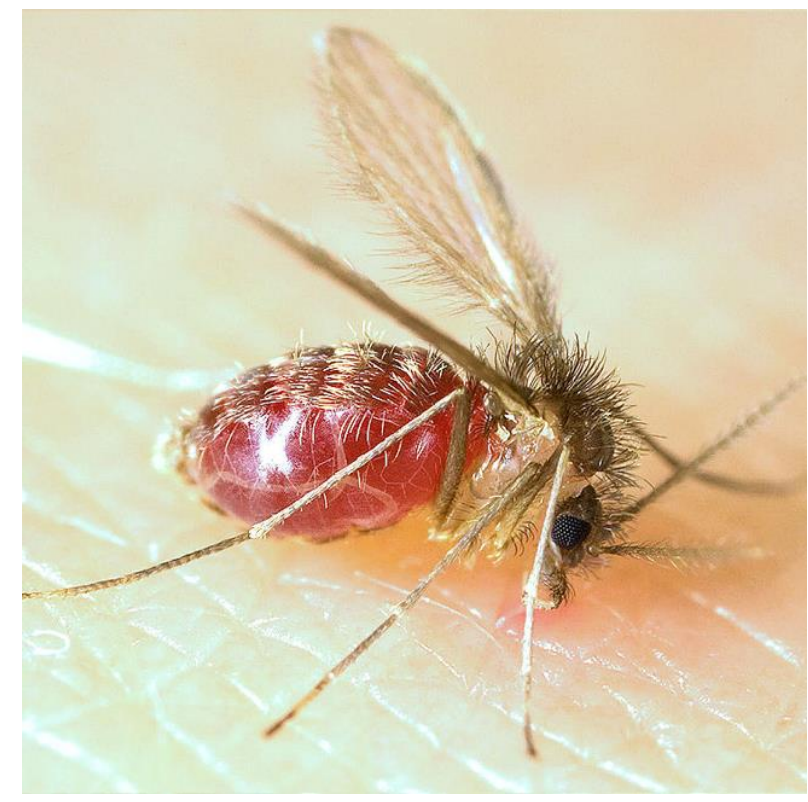

Figura 1. Fêmea de Lutzomyia (Lutzomyia) longipalpis realizando repasto sanguíneo (Crédito da imagem: Ray Wilson, Liverpool School of Tropical Medicine).

A maior parte dos flebotomíneos inicia suas atividades no período crepuscular e/ou noturno, quando saem de seus abrigos para se alimentarem. A superfície corporal é bastante permeável, pois 
apresenta um revestimento quitinoso delgado. Essa característica expõe esses dípteros, de maneira sensível, a grandes variações de temperatura e umidade sendo necessárias condições microclimáticas estáveis semelhantes à de seus abrigos como, por exemplo, tocas ou ninhos de animais, fendas de árvores e rochas, serrapilheira e outros locais protegidos da luz (Forattini, 1973; Brazil \& Brazil, 2003).

Em relação ao hábito alimentar, ambos os sexos precisam de carboidratos como fonte de energia. Esses são usualmente provenientes de seiva vegetal ou secreções açucaradas de afídeos ou outros hemípteros, entretanto as fêmeas dos flebotomíneos praticam a hematofagia, exceto raras espécies autógenas (não hematófagas), pois necessitam de sangue para maturação ovariana o que as tornam vetoras de patógenos (Killick-Kendrick, 1999). Essa ingestão de sangue pode variar entre as espécies ocorrendo apenas uma vez entre as posturas ou múltiplas vezes durante um único ciclo de oviposição, tornando-as vetoras mais importantes. Por exemplo, espécies peridomiciliares como Lutzomyia longipalpis e Phlebotomus papatasi podem realizar vários repastos sanguíneos antes da maturação e postura dos ovos (Ready, 2013). Outra variação nos hábitos alimentares dessas fêmeas é que algumas espécies realizam o repasto exclusivamente em determinados vertebrados e outras apresentam hábitos ecléticos picando indiferentemente diversas espécies de mamíferos (Sherlock, 2003; Ready, 2013).

A subfamília Phlebotominae representa um dos grupos de insetos de grande importância médicoveterinária, sendo algumas de suas fêmeas vetoras naturais de agentes etiológicos de doenças, como os protozoários do gênero Leishmania Ross, 1903 e outros tripanossomatídeos (Herpetomonas, Blastocrithidia, Trypanosoma e Endotrypanum), bactérias do gênero Bartonella e vários arbovírus como Vesiculovirus, Phlebovirus e Orbivirus (Forattini, 1973; Sherlock, 2003; Shaw et al., 2003; Rocha et al., 2010; Ready, 2013). As mais importantes e comuns dessas doenças transmitidas pelos flebotomíneos são resultantes da infecção por diferentes espécies de protozoários tripanossomatídeos digenéticos do gênero Leishmania (Kinetoplastida, Trypanosomatidae), parasitos obrigatórios de células do sistema monocítico fagocitário (Pimenta et al., 2003).

É importante destacar que esses flebotomíneos são naturalmente silvestres, mas as mudanças ambientais provocadas por fenômenos naturais ou pela intervenção humana, como a destruição de matas nativas, têm alterado os habitats naturais destes insetos e modificam a situação ecológica entre vetores, parasitos e hospedeiros (Pessoa et al., 2007). A ocupação humana desordenada e invasão de áreas florestais propiciaram a aproximação desses vetores do peridomicílio e domicílio permitindo que, cada vez mais, os ciclos das leishmanioses ocorram de forma extrasilvestre 
podendo aumentar a extensão e o número de casos das doenças (Madeira et al., 2003; Queiroz et al., 2012).

\subsection{As Leishmanioses}

As leishmanioses estão incluídas na lista de Doenças Negligenciadas, sendo endêmicas em mais de 98 países e territórios onde há um total 350 milhões de pessoas que se encontram em situação de risco e 12 milhões de casos de infecção, estando ausentes apenas na Nova Zelândia e no sul do Pacífico (Akhoundi et al., 2016). Entre as regiões endêmicas de cinco continentes, estima-se uma taxa de incidência variando de 900 mil a 1,6 milhão de novos casos anualmente dos quais 200 a 400 mil são de Leishmaniose Visceral (LV) e 700 mil a 1,2 milhão de Leishmaniose Tegumentar (LT) (Alvar et al., 2012).

Já foram descritas 53 espécies de Leishmania pertencentes a cinco subgêneros e complexos (Leishmania, Viannia, Sauroleishmania, complexo L. enriettii e Paraleishmania). Desse total, 31 espécies parasitam mamíferos, sendo que pelo menos 20 delas infectam seres humanos. As leishmanioses apresentam distintas manifestações clínicas que variam de acordo com a espécie que está parasitando, o hospedeiro mamífero e o tropismo da espécie quanto ao tecido (Akhoundi et al., 2016). A LV acomete principalmente o baço, o fígado e a medula do hospedeiro mamífero enquanto que a LT acomete principalmente a pele e mucosas (Brasil, 2006, 2007; WHO, 2010a, 2010b).

\subsubsection{Leishmaniose Visceral}

A LV é considerada uma das doenças mais importantes da atualidade devido a sua incidência e alta letalidade, quando não se institui o tratamento adequado e em crianças desnutridas, sendo também considerada emergente em indivíduos portadores da infecção pelo vírus da imunodeficiência adquirida - HIV (Gontijo \& Melo, 2004). Clinicamente, a doença é caracterizada por acessos de febre prolongada, perda substancial de peso, hepatoesplenomegalia, linfodenopatia, anemia com leucopenia, escurecimento da pele em algumas áreas e mais raramente nódulos ou úlceras cutâneas (Figuras 2A e B) (Brasil, 2006; WHO, 2010a). 

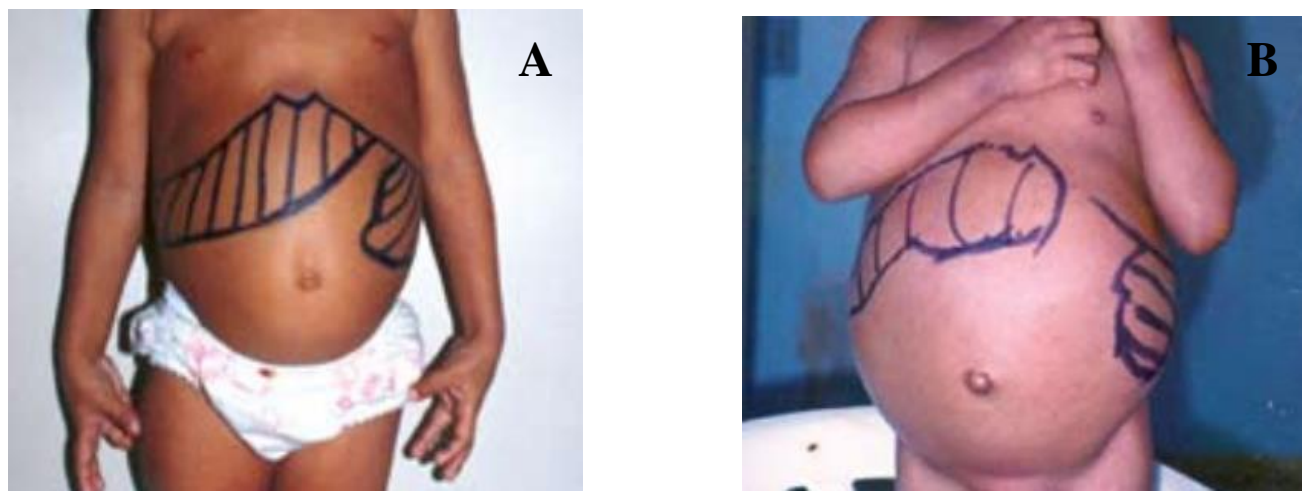

Figura 2. Em "A" e "B" manifestações clínicas de Leishmaniose Visceral acometendo crianças. As áreas marcadas indicam fígado e baço inflamados (Fonte: Brasil, 2006).

Aproximadamente $90 \%$ dos casos ocorrem em apenas seis países: Índia, Bangladesh, Sudão, Sudão do Sul, Etiópia e Brasil. A LV atinge principalmente as populações pobres e, embora existam métodos de diagnóstico e tratamento específicos, grande parte da população não tem acesso a estes procedimentos, o que eleva os índices de mortalidade (Gontijo \& Melo, 2004; Akhoundi et al., 2016).

No Brasil, era primariamente caracterizada como uma doença de caráter rural, mas recentemente com expansão para áreas urbanas se tornou um crescente problema de saúde pública, sendo uma endemia em processo de expansão geográfica. Nos últimos anos, casos da doença vêm sendo registrados em centros urbanos como Rio de Janeiro (RJ), Corumbá (MS), Belo Horizonte (MG), Araçatuba (SP), Palmas (TO), Três Lagoas (MS), Campo Grande (MS), entre outros. A LV pode ser encontrada em todas as regiões do país tendo 78.433 casos registrados entre os anos de 1990 e 2014 (Sinan/SVS/MS), a maioria (70\%) na Região Nordeste (Brasil, 2006, 2016a; Alvar et al., 2012). Entre 1990 e 2006, aproximadamente 50.060 casos de LV foram registrados no Brasil, o que corresponde a 90\% de todos os casos de LV nas Américas (Romero \& Boelaert, 2010).

O agente etiológico da LV no Brasil é Leishmania (Leishmania) infantum [= Leishmania (Leishmania) infantum chagasi] tendo Lutzomyia (Lutzomyia) longipalpis como principal espécie vetora (Tabela 1), sobretudo pela sua adaptação as áreas urbanas e sua ampla distribuição que é coincidente com os casos da doença no país. Nos estados do Mato Grosso e Mato Grosso do Sul a espécie Lutzomyia (Lutzomyia) cruzi e, secundariamente, Lutzomyia (Lutzomyia) forattinii também foram associadas à transmissão dessa doença (Galati et al., 1997; Santos et al., 1998; Pita-Pereira, 2008). Em áreas com ocorrência de LV, onde não foram encontradas as espécies citadas, a alta 
incidência de Migonemyia migonei levou a hipótese de que essa espécie poderia ser vetora como, por exemplo, em Pernambuco (Carvalho et al., 2010).

Tabela 1. Prováveis ciclos de transmissão das leishmanioses encontradas no Brasil. Adaptado de WHO, 2010a.

\begin{tabular}{|c|c|c|c|}
\hline Leishmania spp. & Forma clínica & Vetor comprovado ou suspeito & $\begin{array}{c}\text { Reservatório animal comprovado } \\
\text { ou suspeito }\end{array}$ \\
\hline L. (L.) infantum & LV & $\begin{array}{l}\text { Lu. longipalpis, Lu. cruzi, } \\
\text { Lu. forattinii, Lu.almerioi }\end{array}$ & $\begin{array}{c}\text { Canis lupus familiaris, Felis catus, } \\
\text { Lycalopex vetulus, Cedocyon thous, } \\
\text { Didelphis albiventris, }\end{array}$ \\
\hline L. (L.) amazonensis & LTA $(\mathrm{LAD})^{1}$ & $\begin{array}{l}\text { Bichromomyia flaviscutellata, } \\
\text { Bi. reducta, Bi. olmeca nociva }\end{array}$ & Proechimys spp., Oryzomys spp., Wiedomys spp. \\
\hline L. $(V$.$) braziliensis$ & $\operatorname{LTA}(\mathrm{LMC})^{2}$ & $\begin{array}{l}\text { Ny. whitmani, Ny. intermedia, } \\
\text { Ny. neivai, Psychodopygus } \\
\text { complexus, Ps. wellcomei, Mg. } \\
\text { migonei, Pintomyia fischeri }\end{array}$ & $\begin{array}{l}\text { Canis lupus familiaris, Rattus rattus, Akodon } \\
\text { arviculoides, Necromys spp., Nectomys } \\
\text { spp.,Thrichomys spp. }\end{array}$ \\
\hline L. $(V$.$) guyanensis$ & $\mathrm{LTA}(\mathrm{LMC})^{2}$ & $\begin{array}{l}\text { Nyssomyia umbratillis, } \\
\text { Ny. anduzei }\end{array}$ & $\begin{array}{l}\text { Choloepus spp., Tamandua spp., Didelphis spp., } \\
\text { Proechimys spp. }\end{array}$ \\
\hline L. (V.) lainsoni & LTA & $\begin{array}{l}\text { Trichophoromyia ubiquitalis } \\
\text { Ps. squamiventris, Ps. }\end{array}$ & Agouti paca \\
\hline L. (V.) naiffi & LTA & $\begin{array}{c}\text { paraensis, Ps. amazonensis, } \\
\text { Ps. ayrozai }\end{array}$ & Dasypus novemcinctus \\
\hline L. (V.) shawi & LTA & Ny. whitmani & $\begin{array}{c}\text { Cebus apella, Chiropotes satanus, Nasua nasua, } \\
\text { Bradypus tridactylus, Choloepus didactylus }\end{array}$ \\
\hline L. $(V$.$) lindenbergi$ & LTA & Ny. antunesi & Desconhecido \\
\hline
\end{tabular}

${ }^{1}$ Leishmaniose anérgica difusa e ${ }^{2}$ Leishmaniose mucocutânea

A eliminação da LV ainda não é uma meta realista considerando a complexidade das características epidemiológicas e o conhecimento insuficiente sobre os vários elementos que compõem a cadeia de transmissão resultando em estratégias de controle pouco efetivas baseadas no diagnóstico e tratamento precoce dos casos, diminuição da população dos insetos vetores e eliminação dos reservatórios (Brasil, 2006). No entanto, de acordo com Romero \& Boelaert (2010), para melhorar o controle da LV são necessárias medidas mais abrangentes: suporte governamental como, fundos para o controle de LV, desenvolvimento de uma política de controle regional coerente e investimentos para a gestão dos casos e sistemas de vigilância epidemiológica. Por fim, a implementação de uma agenda de pesquisa focada é essencial para suportar qualquer iniciativa de controle. 


\subsubsection{Leishmaniose Tegumentar}

A Leishmaniose Tegumentar (LT) tem ampla distribuição mundial, principalmente no continente americano sendo considerada pela Organização Mundial de Saúde (OMS), como uma das seis mais importantes doenças infecciosas, pelo elevado número de casos e capacidade de produzir deformidades (Brasil, 2007). A forma cutânea é a mais comum dentre as formas clínicas da doença e 70 - 75\% de sua taxa alta de incidência ocorre, principalmente, em 10 países: Afeganistão, Argélia, Colômbia, Brasil, Irã, Síria, Etiópia, Sudão do Norte, Costa Rica e Peru (Akhoundi et al., 2016).

No Brasil, a Leishmaniose Tegumentar Americana (LTA) está presente em todas as Unidades Federativas do país onde foram registrados 655.695 casos entre 1990 e 2014, resultando em uma média de aproximadamente 27 mil casos por ano (Sinan/SVS/MS). Diferentemente da LV, onde a maior parte dos casos está concentrada na região Nordeste, na LTA, os casos estão mais distribuídos, a região Norte com maior número de casos, seguida pela região Nordeste, CentroOeste, Sudeste e Sul (Brasil, 2007, 2016b).

A LTA é uma enfermidade polimórfica de pele caracterizada pela presença de lesões ulceradas indolores (Figuras 3A e B), únicas e de duração limitada (forma cutânea simples), lesões nodulares (tipo difusa) ou lesões mucocutâneas que afetam a mucosa nasofaringeana (Murray et al., 2005). A LTA possui uma diversidade de agentes etiológicos, de reservatórios e de vetores apresentando diferentes padrões de transmissão, o que torna o seu controle bastante complexo (Brasil, 2007).
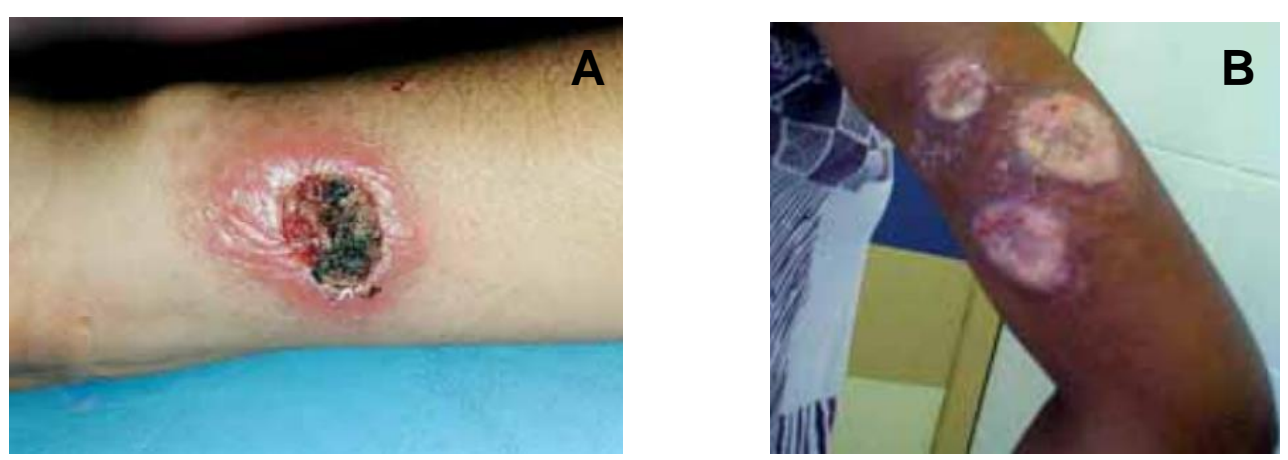

Figura 3. Manifestações clínicas de Leishmaniose Tegumentar. Em “A” lesão cutânea localizada no punho e em “B” lesão cutânea múltipla localizada no braço (Fonte: Brasil, 2007). 
Com relação ao agente etiológico da LTA, no Brasil foram identificadas sete espécies de Leishmania pertencentes aos subgêneros Viannia e Leishmania (Tabela 1). Dessas, as três principais são (Brasil, 2007, 2016b):

- Leishmania (Viannia) braziliensis: primeira espécie de Leishmania descrita e incriminada como agente etiológico da LTA. Do ponto de vista epidemiológico, é a espécie mais importante, pois possui ampla distribuição que vai da América Central até o norte da Argentina. No Brasil, está amplamente distribuída sendo encontrada em todas as regiões do país.

- Leishmania (Leishmania) amazonensis: vem ocorrendo em florestas primárias e secundárias na área da Amazônia legal que inclui o Maranhão e o norte do Tocantins, Amazonas, Pará e Rondônia, mas também é reportada na Bahia, Minas Gerais, São Paulo, Goiás, Mato Grosso do Sul e Paraná.

- Leishmania (Viannia) guyanensis: registrada nos estados do Acre, Amapá, Roraima, Amazonas e Pará estendendo-se pelas Guianas. Ocorre em florestas primárias de terra firme com a transmissão podendo ocorrer durante todo ano.

Dentro do subgênero Viannia, existem outras espécies descritas mais recentemente: Leishmania (Viannia) lainsoni que ocorre nos estados do Pará, Rondônia e Acre; Leishmania (Viannia) naiffi ocorrendo nos estados do Pará e Amazonas; Leishmania (Viannia) shawi com casos humanos registrados no Pará e Maranhão e Leishmania (Viannia) lindenbergi identificada no Pará.

As principais espécies de flebotomíneos envolvidas na transmissão da LTA são: Bichromomyia flaviscutellata, Nyssomyia whitmani, Nyssomyia umbratilis, Nyssomyia intermedia, Nyssomyia neivai, Psychodopygus wellcomei e Migonemyia migonei (Brasil, 2007). Cabe destacar que as espécies são consideradas importantes vetoras por atenderem aos critérios que atribuem a capacidade vetorial: grau de antropofilia, distribuição espacial coincidente com a da doença, infecção natural pela mesma espécie de Leishmania que infecta o homem, atração por mamíferos reservatórios de Leishmania, transmissão experimental mantendo todas as etapas do desenvolvimento parasitário e capacidade do flebotomíneo infectar e transmitir experimentalmente o parasito e, mais recentemente, desenvolvimento de modelos matemáticos demonstrando que o vetor é essencial para manter a transmissão com ou sem o envolvimento de outros vetores e, demonstrando também, que a incidência da doença cai na medida que diminui a densidade do vetor específico (Rangel \& Lainson, 2003; Brasil, 2007; Ready, 2013). 
Diante dessas informações, evidencia-se a grande importância médica dos flebotomíneos como transmissores de espécies de Leishmania, especialmente no Brasil, já que nenhuma outra nação no mundo detém tamanha diversidade de flebotomíneos (Killick-Kendrick, 2003). Dessa forma, estudos relacionados à biologia, distribuição, eco-epidemiologia e taxonomia desses insetos são bastante relevantes e valorosos.

\subsection{Classificação dos flebotomíneos}

Com relação à taxonomia desse grupo, estima-se que existam 988 espécies e subespécies válidas de flebotomíneos em todos os continentes, exceto Antártica (Bates et al., 2015), onde cerca de 98 delas são incriminadas como vetoras. Nas Américas, as primeiras espécies de flebotomíneos foram descritas por Coquillett (1907), e até 1940, somente 33 espécies eram conhecidas. A partir da descoberta de que algumas espécies estavam envolvidas com a transmissão de agentes patogênicos ocorreu um grande aumento dos estudos relacionados a esses insetos. Entretanto, ainda não há consenso sobre a taxonomia geral desse grupo, especialmente com relação às espécies neotropicais (Young \& Duncan, 1994; Killick-Kendrick, 1999; Galati 2003, WHO, 2010a).

No Velho Mundo a classificação das espécies é geralmente mais aceita e menos controversa do que a das espécies do Novo Mundo. São reconhecidos três gêneros: Phlebotomus Rondani \& Berté, 1840 (grupo que possui as espécies vetoras das leishmânias), Sergentomyia França \& Parrot, 1920 e Chinius, Leng, 1987. Uma nova classificação foi proposta por Rispail \& Léger (1998) sugerindo a elevação de quatro subgêneros em gêneros, sendo estes Australophlebotomus, (Theodor, 1948), Idiophlebotomus (Quate \& Fairchild, 1961), Spelaeophlebotomus (Theodor, 1948) e Spelaeomyia (Theodor, 1948).

Para os flebotomíneos do Novo Mundo, a classificação do grupo tem sido mais controversa. Theodor (1948) propôs a divisão dos flebotomíneos em dois gêneros Brumptomyia França \& Parrot, 1921 e Lutzomyia França \& Parrot, 1924. Neste mesmo ano, foi descrito o gênero Warileya Hertig, 1948 e no ano seguinte, Hertigia Fairchild, 1949. Barretto (1962) adotou os três primeiros gêneros e insere Hertigia em outra subfamília, Bruchomyiinae Alexander, 1920. Theodor (1965) em sua nova proposta de classificação adotou os quatro gêneros, assim como Martins et al. (1978). Todavia Lewis et al. (1977) e Young \& Duncan (1994), reconheceram Lutzomyia (onde se encontram as espécies vetoras) composto por 15 subgêneros e 11 grupos de espécies, Brumptomyia e Warileyia, 
tendo Hertigia como subgênero. Essa classificação é mais utilizada pela maior parte dos pesquisadores, porém ela tem sido questionada por não determinar as relações evolutivas entre as espécies, particularmente do importante gênero Lutzomyia (Galati, 2003; Rangel \& Lainson, 2009; WHO, 2010a).

Uma segunda e mais atual fonte de consulta para a classificação de flebotomíneos é o trabalho publicado em 1995 por Galati, onde por meio de uma análise filogenética baseada em 88 caracteres morfológicos, as 464 espécies de flebotomíneos neotropicais foram agrupadas em 22 gêneros, 20 subgêneros, 3 grupos de espécies e 28 séries. É importante destacar que as espécies vetoras que antes estavam contidas apenas no gênero Lutzomyia (sensu Young \& Duncan, 1994), nessa nova classificação, estão distribuídas em três subtribos: Sergentomyiina Artemiev, 1991, Lutzomyiina Abonnenc \& Leger, 1976 e Psychodopygina Galati, 1995 e em vários gêneros com destaque para: Lutzomyia, Migonemyia, Pintomyia, Bichromomyia, Psychodopygus, Nyssomyia e Trichophoromyia (Galati, 2003; Pinto et al., 2010; WHO, 2010a). De acordo com essa classificação de Galati (1995, 2003), o gênero Lutzomyia está subdividido em quatro subgêneros: Castromyia Mangabeira, 1942, Helcocyrtomyia Barretto, 1962, Tricholateralis Galati, 1995 e Lutzomyia (sensu stricto).

Em 2014, Galati propôs uma nova classificação para os flebotomíneos baseada na revisão de seu trabalho anterior. De acordo com essa classificação, a tribo Hertigiini contém 2 subtribos com apenas 28 espécies não vetoras de leishmanioses em humanos classificadas em 5 gêneros. Já a tribo Phlebotomini, inclui 931 espécies existentes classificadas em 30 gêneros e em seis subtribos: Phlebotomina, Australophlebotomina, Brumptomyiina, Sergentomyiina, Lutzomyiina e Psychodopygina (Bates et al., 2015; Akhoundi et al., 2016).

\subsection{O subgênero Lutzomyia}

Lutzomyia "sensu stricto" possui um total de 23 espécies (20 espécies válidas e três com status taxonômico incerto) das quais 14 ocorrem no Brasil (Galati, 2014). Esse subgênero merece uma atenção especial por conter a principal espécie vetora de $L$. (L.) infantum, agente da LV na América, Lu. longipalpis. Além desta, duas outras espécies contidas nesse subgênero também foram associadas à transmissão da LV nos estados de Mato Grosso e Mato Grosso do Sul sendo elas $L u$. 
cruzi e Lu. forattinii (Galati et al., 1997; Santos et al., 1998; Rangel \& Lainson, 2003; Brasil, 2007; Pita-Pereira, 2008).

Lutzomyia. longipalpis (Figura 1) possui grande importância epidemiológica e ampla distribuição ocorrendo na maioria dos estados brasileiros incluindo Roraima, Pará, Rondônia, Tocantins, Maranhão, Piauí, Ceará, Rio Grande do Norte, Paraíba, Pernambuco, Alagoas, Sergipe, Bahia, Minas Gerais, Espírito Santo, Rio de Janeiro, São Paulo, Goiás, Mato Grosso, Mato Grosso do Sul, Distrito Federal, Paraná e Rio Grande do Sul. É uma espécie com habilidade de ocupar diversos habitats. Adaptou-se facilmente ao peridomicílio, sendo encontrada nos abrigos dos animais domésticos e também no intradomicílio. As fêmeas possuem hábitos ecléticos realizando o repasto em várias espécies de mamíferos, incluindo o homem (Lainson \& Rangel, 2005; Brasil, 2006).

Muitos estudos afirmam que Lu. longipalpis representa um complexo de espécies. Mangabeira (1969) foi o primeiro a notar diferenças morfológicas em machos de diferentes localidades do Brasil. Posteriormente, Ward et al. (1983) confirmaram os achados de Mangabeira; machos coletados no Pará tinham um par de manchas brancas no $4^{\circ}$ tergito abdominal enquanto que os machos coletados no Ceará tinham dois pares de manchas brancas no $3^{\circ}$ e $4^{\circ}$ tergitos. Em seguida, os autores mostraram que as duas formas eram isoladas reprodutivamente sugerindo que poderiam ser espécies crípticas (Ward et al., 1985). Vários trabalhos vêm analisando essa variabilidade entre populações de Lu. longipalpis sobre diversas perspectivas: genética, morfológica, análise de isoenzimas, molecular, bioquímica, estudos sobre acasalamento e também análises morfométricas (Lanzaro et al., 1993; Dujardin et al., 1997b; Mukhopadhyay et al., 1998; Mutebi et al., 1998; De la Riva et al., 2001; Arrivillaga et al., 2002; Bauzer et al., 2000; Maingon et al., 2003; Souza et al., 2004; Hamilton et al., 2005; Balbino et al., 2006; Araki et al., 2009; Vigoder et al., 2010; Lins et al., 2012; Santos et al., 2013; Santos et al., 2015).

No subgênero Lutzomyia existe um grupo de espécies que são muito próximas morfologicamente (espécies crípticas) com suas fêmeas consideradas indistinguíveis pela morfologia clássica. Esse grupo é formado por Lu. longipalpis, Lu. cruzi e Lu. gaminarai (Bauzer et al., 2007). A identificação dessas fêmeas tem importante implicação médica visto que $L u$. gaminarai não tem sido associada como vetora de Leishmania. Essas espécies têm sido identificadas baseando-se somente na morfologia dos machos e associação dos sexos. Por exemplo, no Mato Grosso do Sul nos municípios onde há presença de Lu. cruzi e Lu. longipalpis o encontro 
de uma fêmea não permite saber de qual espécie se trata (Galati et al., 1997). O mesmo poderia ocorrer com Lu. longipalpis e Lu. gaminarai no Paraná (Silva et al., 2008).

Devido a esse papel como vetores de agentes causadores de doenças, a pesquisa de mais caracteres taxonômicos e métodos para identificação e classificação de flebotomíneos têm sido realizados, principalmente em relação às espécies que são muito próximas morfologicamente, que, em alguns casos, são indistinguíveis pela morfologia clássica. Entre esses métodos alternativos, podemos destacar a morfometria, pelo seu baixo custo e pela qualidade dos resultados alcançados em estudos com flebotomíneos (e.g. Dujardin, 1999a, 2008; De la Riva et al., 2001).

\subsection{Morfometria}

Inicialmente, esse termo se referia a qualquer estudo que analisasse quantitativamente a variação morfológica. A morfometria era baseada na comparação dos valores médios de uma ou mais medidas da estrutura analisada. No entanto, desde a década de 1990, novas técnicas surgiram, permitindo a descrição da variação na forma das estruturas morfológicas entre grupos de indivíduos e entre indivíduos de cada grupo, além das causas das diferenças de forma entre esses organismos, sendo elas de origem ecológica ou filogenética (Monteiro \& Reis, 1999; Dujardin, 2008).

A morfometria pode ser dividida em tradicional e geométrica. A primeira se baseia no estudo da variação e covariação de medidas de distância lineares entre pontos anatômicos (landmarks) homólogos. Contudo, as análises que utilizam essa técnica não capturam muita informação do organismo. A morfometria geométrica se baseia na utilização de coordenadas cartesianas de marcos anatômicos e métodos de superposição para obter a configuração consenso desses pontos homólogos. A vantagem da utilização de coordenadas é poder analisar a forma das estruturas, apresentar de maneira gráfica suas diferenças e, inclusive, indicar com maior precisão em quais regiões se concentram as variações, possibilitando a reconstrução da forma após a realização das análises multivariadas (Rohlf \& Marcus, 1993).

As análises multivariadas, como Análise de Componentes Principais (ACP) e Análise de Funções Discriminantes (AFD), são utilizadas para verificar a formação ou não de grupos homogêneos, envolvendo os espécimes em estudo. A ACP possui o objetivo de verificar se alguns componentes podem explicar a maior parte da variação das características (Monteiro \& Reis, 1999). $\mathrm{Na}$ AFD, cada função discriminante representa um único padrão de variação na forma e por meio 
dela é possível plotar espécimes em um espaço discriminante de forma obtendo-se um mapa fatorial onde os indivíduos são agrupados. A distância entre os grupos formados está relacionada com a probabilidade de pertencer a um determinado grupo. Logo, em grupos bem definidos as chances de reclassificações corretas são mais altas (Francoy \& Imperatriz-Fonseca, 2010). Para verificar a eficiência do modelo discriminante, as reclassificações podem ser testadas pela estatística Kappa (Landis \& Koch, 1977), gerando um índice que avalia a eficiência do modelo discriminante.

A morfometria geométrica representa uma nova abordagem para estudar a variação morfológica, cuja utilização e importância começaram a ser percebidas apenas nos últimos anos. Já é considerado um método importante em análises taxonômicas e sistemáticas de insetos de interesse em saúde pública (Dujardin, 2008). As principais vantagens da utilização dessa técnica são a velocidade da coleta de material de teste, pois várias imagens podem ser digitalizadas e analisadas de forma rápida, o baixo custo do processo e o fato de que o material pode ser obtido tanto de exemplares secos quanto frescos (Lyra et al., 2010).

Sintetizando, essa técnica permite analisar a forma das estruturas, assim como apresentar de maneira gráfica e clara as diferenças de forma, além de indicar com maior precisão em quais regiões se concentra a sua variação. Sendo dessa maneira, uma técnica complementar, não só para estudos de taxonomia alfa, bem como auxiliando na interpretação das análises moleculares (Calle et al., 2008).

Segundo Monteiro \& Reis (1999), para a realização desses estudos morfométricos, as asas dos insetos são consideradas estruturas muito apropriadas, pois possuem características que favorecem sua utilização nesse tipo de trabalho como, por exemplo, sua forma predominantemente bidimensional e o grande número de marcos anatômicos do tipo I (encontro entre dois tecidos) possíveis de serem inseridos nas veias alares.

As técnicas de morfometria têm sido muito aplicadas em diversos estudos envolvendo insetos de interesse médico como os triatomíneos (Dujardin, 2008; Gurgel-Gonçalves et al., 2008), mosquitos do gênero Anopheles (Calle et al., 2008; Lorenz et al., 2012), Aedes (Jirakanjanakit \& Dujardin, 2005; Vidal et al., 2012) e Culex (Demari-Silva et al., 2014) entre outros trabalhos. Com relação aos flebotomíneos, a utilização dessa técnica pode ser vista na literatura em vários trabalhos que a empregam para resolução de problemas taxonômicos, sistemáticos e descrições de variações morfológicas e populacionais. 
Estudos pioneiros que aplicaram a morfometria para identificação de flebotomíneos foram realizados por Lane e Ready (1985) para diferenciação entre Ps. wellcomei e Ps. complexus; Lebbe et al. (1991) para caracterização e morfologia da asa de 32 espécies de flebotomíneos; GebreMichael e Lane (1993) com o objetivo de diferenciar Phlebotomus martini e Ph. celiae; GebreMichael e Medhin (1997) para diferenciar Ph. duboscqi e Ph. bergeroti; Añez et al. (1997) utilizaram a morfometria para diferenciação de Pintomyia townsendi, Pi. spinicrassa e Pi. youngi. Por fim, ainda na década de 1990, Dujardin et al. (1999a) mostraram que, com essa técnica, foi possível separar duas espécies crípticas de Psathyromyia runoides da Bolívia e também que essas duas espécies eram diferentes de Pa. inflata.

Desde então, os estudos de flebotomíneos envolvendo a utilização de morfometria vem sendo cada vez mais comuns na literatura destacando as várias aplicações dessa técnica. Por exemplo, Dujardin \& Le Pont (2000) demonstram claras diferenças entre subespécies de Ps. carrerai indicando que a morfometria pode ser utilizada para analisar variações geográficas e divergências evolutivas. Cazorla \& Acosta (2003) ressaltam a importância dessa técnica para grupos com problemas de identificação mostrando a diferenciação de espécies de Lutzomyia (Micropygomyia) utilizando sete variáveis de diferentes estruturas (cabeça, asas e genitália). Dujardin et al. (2005), apresentaram evidências morfométricas de um processo de especiação em Pa. aragaoi na Bolívia. Posteriormente, Cazorla (2009) mostrou a diferenciação entre as fêmeas de duas espécies crípticas de Lutzomyia (Helcocyrtomyia) baseada em apenas três caracteres das asas.

A morfometria também tem sido aplicada para analisar variação populacional intraespecífica. Florin et al. (2011), realizaram análises morfométricas e moleculares em espécimes de $P$ a shannoni coletados em sete áreas geograficamente diferentes do sudeste dos Estados Unidos para verificar o grau de divergência entre eles em cada localidade. Posteriormente, Zapata et al. (2012) desenvolveram um amplo estudo da série Guyanensis da Bacia Amazônica Equatoriana combinando dados morfológicos, morfométricos e moleculares e sugerindo a existência de uma nova espécie. Um trabalho recente realizado por Santos et al. (2015), investigou por meio de análises morfométricas populações do complexo Longipalpis no Mato Grosso do Sul, destacando mais uma vez, o potencial da morfometria para diferenciar populações simpátricas.

Finalmente, alguns estudos utilizaram a morfometria para analisar a geometria alar de flebotomíneos. De la Riva et al. (2001) utilizaram essa técnica para estudar variação entre populações de Lutzomyia longipalpis da Bolívia e Nicarágua coletadas em diferentes habitats (silvestre e peridoméstico) e com diferentes características fenotípicas (uma ou duas manchas nos 
tergitos abdominais). Neste trabalho foi possível discriminar dois grupos de acordo com a geometria da asa, porém um desses grupos foi formado por populações com uma ou duas manchas nos tergitos, questionando essa característica como critério para diferenciação de espécies do complexo Longipalpis. Aytekin et al. (2007) investigaram a variação fenotípica entre espécies do gênero Phlebotomus do sul da Turquia também utilizando a morfometria geométrica. Essa técnica também foi empregada por Prudhomme et al. (2012) para estudar as variações fenotípicas entre as populações de $P h$. papatasi provenientes de diferentes regiões do Marrocos. Um estudo mais recente (Godoy et al. 2014) utilizando morfometria geométrica e considerando a classificação de Galati (2003) mostrou claras diferenças na geometria alar de espécies vetoras de LTA no Brasil pertencentes aos gêneros Nyssomyia, Migonemyia e Bichromomyia. Finalmente, Shimabukuro et al. (2016) na descrição da fêmea de Martinsmyia minasensis demonstraram que esta pode ser diferenciada daquelas de Mt. oliveirai por morfometria de asas, as quais foram corroboradas por análises de taxonomia alfa. 


\subsection{Justificativa}

O emprego da morfometria alar pode ajudar a resolver problemas taxonomicamente complexos como a diferenciação de algumas espécies do subgênero Lutzomyia (sensu Galati, 2003). Como mencionado anteriormente, apesar dos vários estudos utilizando diferentes abordagens, ainda não há consenso sobre o número de espécies crípticas do complexo Longipalpis.

Além disso, no Brasil pelo menos três espécies desse subgênero estão associadas com a transmissão da LV: Lu. longipalpis, Lu. cruzi e Lu. forattinii. Elas fazem parte do grupo de espécies que são muito próximas morfologicamente com suas fêmeas consideradas indistinguíveis pela morfologia clássica. Essas espécies, apesar da grande semelhança morfológica, podem desempenhar papéis distintos quando à capacidade de atuar como vetoras. Logo, a identificação dessas fêmeas tem importante implicação médica.

A correta identificação taxonômica é um componente crucial para qualquer estudo epidemiológico, com implicações no desenvolvimento de estratégias para o controle da LV. Portanto, métodos confiáveis de identificação taxonômica são extremamente necessários e neste sentido, a morfometria geométrica de asas pode auxiliar como uma técnica importante.

Ainda, a morfometria alar de diferentes gêneros e subgêneros da subfamília Phlebotominae poderá fornecer importantes parâmetros para contribuir com evidências que reforçam ou não os agrupamentos filogenéticos desse importante grupo de vetores.

Futuramente, essa ferramenta também poderá ser inserida nos laboratórios de entomologia estaduais e municipais para identificação específica e genérica de flebotomíneos. 


\section{OBJETIVOS}

\subsection{Objetivo geral}

Analisar a geometria alar de espécies do subgênero Lutzomyia "sensu stricto" que ocorrem no Brasil e avaliar se essas análises podem ser úteis para identificação das espécies.

\subsection{Objetivos específicos}

- Analisar a variação na forma das asas de espécies de Lutzomyia do subgênero Lutzomyia e comparar com outras espécies de diferentes subgêneros e gêneros;

- Analisar variações intraespecíficas de tamanho e forma entre os sexos;

- Verificar se é possível separar as fêmeas morfologicamente indistinguíveis inseridas no subgênero Lutzomyia por geometria alar;

- Verificar se a quantidade de pontos usados na morfometria influencia a diferenciação entre as espécies;

- Identificar agrupamentos gerados a partir da geometria alar e verificar se estão de acordo com a chave de identificação de Galati (2003). 


\section{MATERIAL E MÉTODOS}

\subsection{Material de coleção biológica}

Foram utilizados flebotomíneos de 18 espécies depositados na Coleção Entomológica do Laboratório de Entomologia em Saúde Pública da Universidade de São Paulo (FSP-USP-LESPPhlebotominae) e na Coleção de Flebotomíneos do Centro de Pesquisas René Rachou, Minas Gerais (FIOCRUZ-COLFLEB). Dessas, 12 pertencentes ao subgênero Lutzomyia "sensu stricto" ocorrendo no Brasil: Lu. alencari, Lu. almerioi, Lu. cavernicola, Lu. cruzi, Lu. dispar, Lu. forattinii, Lu. gaminarai, Lu. ischnacantha, Lu. lichyi, Lu. ischyracantha, Lu. longipalpis, Lu. renei. Além dessas, Lu. battistinii do mesmo subgênero (ocorrência no Peru), duas espécies do subgênero Helcocyrtomyia sendo elas Lu. ayacuchensis e Lu. tejadai e espécies de outros gêneros: Micropygomyia quinquefer, Brumptomyia brumpti e Brumptomyia avellari foram utilizadas como grupos externos na análise.

Os espécimes foram provenientes de várias localidades que estão listadas na Tabela 2 (para mais informações sobre as localidades consultar apêndice). Procurou-se utilizar 40 indivíduos de cada espécie sendo 20 fêmeas e 20 machos, mas isso não foi possível em todos os casos, pois ou não havia exemplares suficientes na coleção ou as asas não estavam em bom estado de montagem para análise. Para Lu. longipalpis, Lu. cruzi e Lu. gaminarai as fêmeas, que são indistinguíveis morfologicamente, foram identificadas levando em conta suas procedências e a identificação do macho coletado no mesmo local.

Os exemplares utilizados já estavam previamente montados e preservados em lâminas. Inicialmente, foi feita uma triagem para selecionar os indivíduos com asas em melhor estado para realização das análises de morfometria geométrica. Priorizou-se utilizar a asa direita dos espécimes analisados. Nos casos em que a asa direita estava danificada a asa esquerda foi utilizada após um giro de $180^{\circ}$ da asa fotografada.

As asas dos flebotomíneos (machos e fêmeas) foram fotografadas com uma câmera digital (Sony ${ }^{\circledR}$ Cyber-shot 14.1 Mp) acoplada a um microscópio (aumento: 100x). Essa mesma câmera foi utilizada para todas as fotografias, porém não foi possível utilizar o mesmo modelo de microscópio visto que cada laboratório possuía um equipamento diferente sendo o da Faculdade de Saúde Pública - USP um microscópio Olympus BX51 e o da FIOCRUZ - MG um microscópio Axio Scope.A1 - Zeiss. 
Tabela 2. Lista das espécies analisadas no trabalho com número de fêmeas e machos utilizados, localidade de origem e a coleção de procedência.

\begin{tabular}{|c|c|c|c|}
\hline \multicolumn{2}{|c|}{ Espécies (indivíduos por sexo) } & Origem & Coleção \\
\hline Lu. alencari & $\left(20 \bigcirc 20 \bigcirc^{\Uparrow}\right)$ & Minas Gerais / Espírito Santo & FIOCRUZ-MG \\
\hline Lu. almerioi & $\left(20+20{ }^{\Uparrow}\right)$ & Mato Grosso do Sul & FSP-USP \\
\hline Lu. cavernicola & $(19+10$ ठ $)$ & Tocantins & FSP-USP \\
\hline Lu. cruzi & $\left(20 \bigcirc 20 \jmath^{\lambda}\right)$ & Mato Grosso do Sul & FSP- USP \\
\hline Lu. dispar & $(19 \subsetneq 20 \hat{\jmath})$ & Mato Grosso do Sul / Piauí & FSP- USP \\
\hline Lu. forattinii & $(17 \subsetneq 20$ ठ̊) & Mato Grosso do Sul & FSP- USP \\
\hline Lu. gaminarai & $\left(20+19 ठ^{\Uparrow}\right)$ & Paraná & FSP- USP \\
\hline Lu. longipalpis & 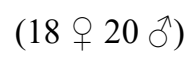 & Mato Grosso do Sul & FSP- USP \\
\hline Lu. ischnacantha & $(19 \bigcirc 18 \precsim)$ & Minas Gerais & FIOCRUZ-MG \\
\hline Lu. ischyracantha & $(20+20 \lesssim)$ & Minas Gerais & FIOCRUZ-MG \\
\hline Lu. renei & $(20 \bigcirc 20 \widehat{\jmath})$ & Minas Gerais & FIOCRUZ-MG \\
\hline Lu. lichyi & $\left(\begin{array}{llll}7 & q & 8 & \bigcirc^{\top}\end{array}\right)$ & Venezuela / Peru & FIOCRUZ-MG \\
\hline Lu. battistinii & $\left(20+12 \delta^{\pi}\right)$ & Peru & FIOCRUZ-MG \\
\hline Lu. ayacuchensis & $(20+20 \precsim)$ & Peru & FIOCRUZ-MG \\
\hline Lu. tejadai & $(20+20 \lesssim)$ & Peru & FIOCRUZ-MG \\
\hline Mi. quinquefer & $(20+20 \lesssim)$ & Minas Gerais / Piauí & FIOCRUZ-MG \\
\hline Br. brumpti & $(20 \bigcirc 20 \lesssim)$ & Minas Gerais / Mato Grosso & FIOCRUZ-MG \\
\hline Br. avellari & $(20$ ㅇ 20 ○) & Minas Gerais/ Mato Grosso do Sul / Maranhão & FIOCRUZ-MG \\
\hline
\end{tabular}

FSP-USP: Coleção Entomológica do Laboratório de Entomologia em Saúde Pública da Universidade de São Paulo. FIOCRUZ-MG: Coleção de Flebotomíneos do Centro de Pesquisas René Rachou, Minas Gerais.

\subsection{Morfometria geométrica das asas}

$\mathrm{Na}$ análise da morfometria geométrica foram utilizados 6 marcos anatômicos (landmarks) para determinar a conformação das asas, sendo esses do tipo 1 que se caracterizam por marcar justaposição de tecidos (Monteiro \& Reis, 1999). Esses marcos anatômicos foram selecionados nas seguintes posições: marco 1 na bifurcação $R 2+3+4$, marco 2 na bifurcação $R 2+3$, marcos 3 , 4 e 5 correspondendo, respectivamente, aos ápices de R1, R5 e M4. Também foi utilizado o marco 6 localizado na bifurcação M1+2 (Figura 4).

A marcação dos pontos foi realizada nas fotos das asas de cada uma das 18 espécies. Todas as imagens foram identificadas com o nome da espécie, o sexo e o número do indivíduo. Os dados 
com as informações de cada exemplar foram catalogados em uma planilha para ajudar na análise dos resultados da geometria alar.

Essas fotos foram armazenadas em uma mesma pasta e com o programa TpsUtil, versão 1.60 (Rohlf, 2013), foi criado um arquivo de texto, com a lista ordenada das fotos por espécie, sexo e número, necessário para continuar a análise com o programa TpsDig2 versão 2.19 (Rohlf, 2015a). Por meio desse programa foi possível fazer a marcação dos 6 landmarks como representado na Figura 4. Como resultado dessa etapa, o arquivo de texto passou a conter as coordenadas cartesianas que foram utilizadas para analisar a geometria alar.

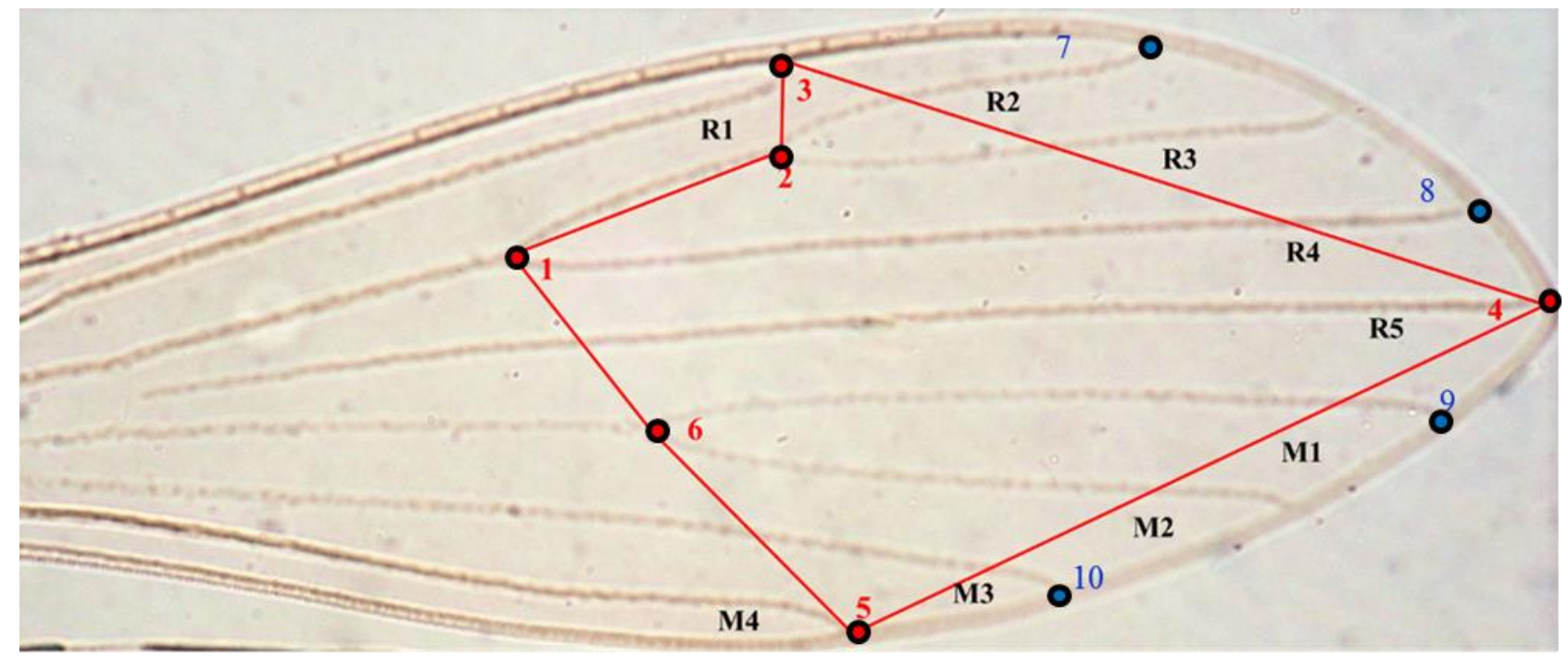

Figura 4. Marcos anatômicos utilizados para análise da morfometria geométrica das asas das espécies de flebotomíneos. Asa de Lutzomyia longipalpis mostrando as veias (R1-5 e M1-4). O polígono vermelho inclui os 6 marcos anatômicos utilizados nas análises com todas as espécies e os pontos em azul indicam os 4 marcos adicionais utilizados nas análises com o grupo de espécies com fêmeas indistinguíveis.

Com a Análise Generalizada de Procrustes (AGP) foi possível remover os efeitos de posição e tamanho. Com essa análise obteve-se uma variável de tamanho (tamanho do centróide) e variáveis de forma (resíduos de sobreposição).

As variáveis de forma foram resultantes da sobreposição das configurações geométricas de cada asa sendo derivada da matriz de coordenadas usando o método de mínimos quadrados (Rohlf, 1996). Dessa forma, foi possível obter uma configuração consenso representando a média de todos 
os indivíduos analisados. Deformações parciais (localizadas) e componentes uniformes (deformações globais) foram posteriormente calculados com base nas deformações de cada asa em relação à configuração consenso. Essas variáveis foram combinadas em uma matriz "W", compondo as variáveis de forma que descreveram a variação nas asas das espécies estudadas (Monteiro \& Reis, 1999). Essas variáveis de forma foram obtidas por meio do programa tpsRelw versão 1.59 (Rohlf, 2015b).

É importante destacar que primeiramente foi feita uma análise geral, onde os procedimentos descritos acima foram aplicados para todas as espécies estudadas de forma conjunta. Posteriormente, foram feitas análises mais específicas considerando apenas as espécies mais próximas na primeira análise. Foi realizada ainda, uma outra análise envolvendo o grupo das fêmeas indistinguíveis morfologicamente, na qual, foram utilizados mais quatro marcos anatômicos (em azul na Figura 4) além dos seis (em vermelho na Figura 4) utilizados no primeiro momento para verificar se seria possível separá-las por geometria alar.

Para verificar a variação no tamanho das asas dos espécimes foi usado o tamanho do centroide (TC), que também é estimado a partir das coordenadas dos marcos anatômicos. Os valores de TC foram extraídos da matriz de coordenadas das asas de cada indivíduo por meio do tpsRelw versão 1.59 (Rohlf, 2015b) e depois transformados (Log).

\subsection{Análises estatísticas}

Após a AGP, foi realizada a Análise de Componentes Principais (ACP) utilizando as deformações parciais para explorar a variação na forma das asas entre os gêneros e subgêneros. A distribuição dos indivíduos de cada espécie no espaço de forma definido pelos dois primeiros componentes principais (PC1 e PC2) foi mostrada graficamente.

Posteriormente, foi utilizada a Análise de Variância (ANOVA) para testar a diferença de tamanho do centróide entre as espécies dos indivíduos fotografados em cada coleção (USP e FIOCRUZ). A análise de variação do tamanho foi realizada separadamente para os espécimes das duas coleções com intuito de evitar possíveis erros nas comparações entre as espécies de cada uma delas, já que não houve como padronizar os equipamentos para o registro das fotos. A diferença de tamanho entre sexos foi avaliada pelo Teste t. Os resultados foram apresentados com diagramas de caixa apresentando a média e variância (desvios-padrão). 
Para testar as diferenças de forma foi utilizada uma ANOVA de procrustes (método para avaliar as quantidades relativas de variação entre indivíduos). As diferenças de forma também foram visualizadas nos grids de deformação gerados pelo programa tpsRelw. Para isso, as deformações relativas associadas aos valores médios dos dois primeiros eixos foram extraídas. Posteriormente, foram feitas Análises de Funções Discriminantes (AFD) para estudar as diferenças de forma entre os grupos especificados "a priori". Mapas fatoriais foram produzidos para mostrar a distribuição dos espécimes no espaço de forma definido pelos dois primeiros fatores discriminantes. Para melhorar a clareza dos gráficos, polígonos convexos foram produzidos para delimitar os agrupamentos formados.

A reclassificação dos espécimes nos grupos de origem foi verificada usando as tabelas de contingência e as estatísticas Kappa (Landis \& Koch, 1977). Em seguida, o sucesso de reclassificação foi avaliado. A contribuição do tamanho para a variação de forma (alometria) foi analisada usando regressão simples dos componentes principais de forma contra os valores de TC das asas analisadas.

Finalmente, foi realizada uma análise para verificar se os agrupamentos morfológicos obtidos por geometria alar neste trabalho estão de acordo com aqueles sugeridos por Galati (2003): i) machos: (Lu. dispar, (Lu. forattinii + Lu. almerioi), (Lu. cavernicola + Lu. renei), Lu. lichyi, Lu. cruzi, Lu. ischnacantha, Lu. longipalpis, Lu. gaminarai, Lu. ischyracantha, Lu. alencari; ii) fêmeas: (Lu. dispar, Lu. lichyi, (Lu. ischnacantha + Lu. cavernicola), Lu. renei, (Lu. almerioi + Lu. forattinii), Lu. ischyracantha, $(L u$. cruzi + Lu. longipalpis $+L u$. gaminarai, + Lu. alencari). Para isso, foram gerados dendrogramas baseados nas distâncias de mahalanobis (geradas após a análise de discriminantes) utilizando o método de UPGMA (Unweighted Pair-Group Method with Aritmetic Average) e a função Cluster no programa Statistica. Esse dendrograma baseado em forma de asas foi comparado com os agrupamentos acima propostos por Galati (2003).

A ANOVA, testes t, Análise Generalizada de Procrustes (AGP), de Componentes Principais (ACP), Funções Discriminantes (AFD), Distância de Mahalanobis e UPGMA foram realizadas utilizando-se os programas Statistica (StatSoft Inc., 2011) e MorphoJ (Klingenberg, 2011). 


\section{RESULTADOS}

\subsection{Variação de tamanho}

A análise do tamanho do centroide mostrou uma diferença significativa entre as espécies tanto para os espécimes da coleção da FSP - USP (ANOVA $F=19,32 ; p<0.001$ ) quanto para os da coleção da FIOCRUZ (ANOVA $F=36,72 ; p<0.001$ ). Entre as espécies analisadas na coleção da USP, Lu. dispar foi significantemente menor que Lu. gaminarai, Lu. longipalpis, Lu. cavernicola e Lu. almerioi para machos e fêmeas (Figura 5). Ao analisar as espécies da coleção da FIOCRUZ observou-se que as asas de $L u$. renei, Lu. battistinii e $L u$. ischnacantha foram claramente menores que as demais espécies (Figura 6).
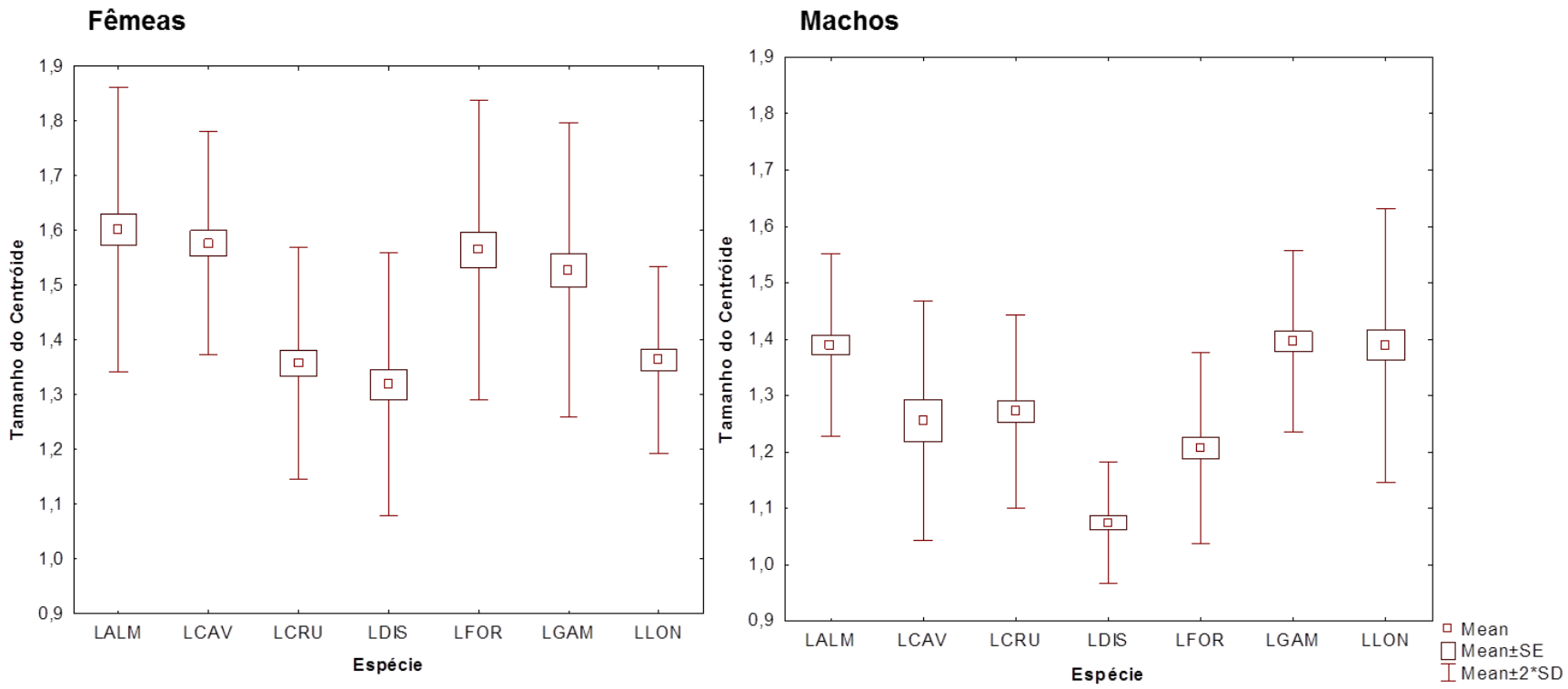

Figura 5. Box-plot mostrando a variação no tamanho do centroide das asas das espécies fotografadas na Universidade de São Paulo. A análise foi feita para fêmeas e machos mostrando a média e desvios-padrão para cada espécie. LAM, Lu. almerioi; LCAV, Lu. cavernicola; LCRU, Lu. cruzi; LDIS, Lu. dispar; LFOR, Lu. forattinii; LGAM, Lu. gaminarai; LLON, Lu. longipalpis. 

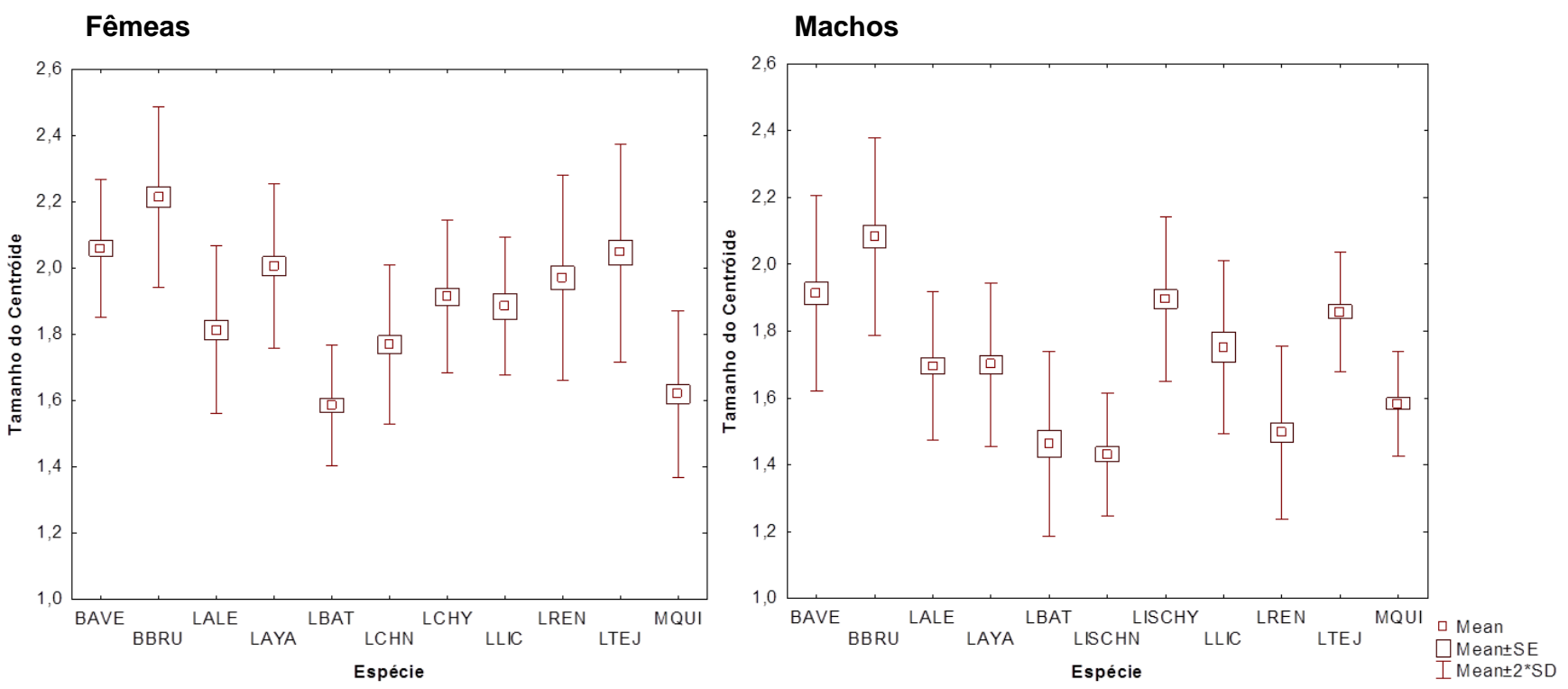

Figura 6. Box-plot mostrando a variação no tamanho do centroide das asas das espécies fotografadas na FIOCRUZ. A análise foi feita para fêmeas e machos mostrando a média e desvios-padrão para cada espécie. BAVE, Br. avellari; BBRU, Br. brumpti; LALE, Lu. alencari; LAYA, Lu. ayacuchensis; LBAT, Lu. battistinii; LCHN, Lu. ischnacantha; LCHY, Lu. ischyracantha; LLIC, Lu. lichyi; LREN, Lu. renei; LTEJ, Lu. tejadai; MQUI, Mi. quinquefer.

Com relação à análise intraespecífica do tamanho do centróide, foi encontrado dimorfismo sexual para quase todas as espécies estudadas exceto Lu. longipalpis, Lu. alencari, Lu. ischyracantha, Lu. lichyi e $M i$. quinquefer que não apresentaram diferença significativa entre machos e fêmeas (Tabela 3). As asas das fêmeas foram maiores que as dos machos para todas as espécies em que foram encontradas diferenças significativas entre os sexos.

Tabela 3. Média do tamanho do centróide para machos e fêmeas de cada uma das espécies analisadas separadas pela coleção de origem.

\begin{tabular}{|c|c|c|c|c|c|}
\hline Espécies & Coleção & Média machos & Média fêmeas & Teste $\mathbf{t}$ & $p$ \\
\hline Lu. almerioi & & 1,39 & 1,60 & $-6,19$ & $<0,01$ \\
\hline Lu. cavernicola & & 1,35 & 1,58 & $-3,66$ & $<0,01$ \\
\hline Lu. cruzi & & 1,27 & 1,36 & $-2,81$ & $<0,01$ \\
\hline Lu. dispar & FSP - USP & 1,07 & 1,32 & $-8,27$ & $<0,01$ \\
\hline Lu. forattinii & & 1,21 & 1,56 & $-9,76$ & $<0,01$ \\
\hline Lu. gaminarai & & 1,39 & 1,53 & $-3,73$ & $<0,01$ \\
\hline Lu. longipalpis & & 1,39 & 1,36 & 0,80 & 0,43 \\
\hline
\end{tabular}




\begin{tabular}{|c|c|c|c|c|c|}
\hline Lu. alencari & & 1,70 & 1,80 & $-2,51$ & 0,02 \\
\hline Lu. ischnacantha & & 1,45 & 1,77 & $-8,25$ & $<0,01$ \\
\hline Lu. ischyracantha & & 1,90 & 1,91 & $-0,45$ & 0,65 \\
\hline Lu. lichyi & & 1,71 & 1,88 & $-2,37$ & 0,03 \\
\hline Lu. renei & & 1,50 & 1,96 & $-9,90$ & $<0,01$ \\
\hline Lu. battistinii & FIOCRUZ - MG & 1,46 & 1,59 & $-3,02$ & $<0,01$ \\
\hline Lu. ayacuchensis & & 1,70 & 1,99 & $-7,19$ & $<0,01$ \\
\hline Lu. tejadai & & 1,88 & 2,03 & $-3,04$ & $<0,01$ \\
\hline Mi. quinquefer & & 1,58 & 1,62 & $-1,25$ & 0,22 \\
\hline Br. brumpti & & 2,06 & 2,22 & $-3,22$ & $<0,01$ \\
\hline Br. avellari & & 1,91 & 2,06 & $-3,62$ & $<0,01$ \\
\hline
\end{tabular}

\subsection{Variação de forma}

A análise de Variância de Procrustes mostrou diferença significativa na forma das asas entre os indivíduos de todas as espécies estudadas $(F=143,68 ; p<0,0001)$. A Análise de Componentes Principais incluindo as 18 espécies mostrou diferenças de forma de asas dos gêneros Micropygomyia, Brumptomyia e Lutzomyia subgêneros Lutzomyia e Helcocyrtomyia (Figura 8). Apenas nos três primeiros componentes principais já foi observada 91,44\% da variação presente na amostra sendo PC1 responsável por 55,95\%, PC2 por 29,38 \% e PC3 por 6,11\%.

Ao analisar as modificações na forma das asas nos componentes principais podemos observar que em PC1 grande parte da variação ocorreu no marco anatômico 3 (ápice de R1) que sofreu acentuado deslocamento para uma região anterior, considerando dos valores negativos para os valores positivos, mostrando a importância desse marco anatômico para separar os gêneros e subgêneros. Também é possível observar uma tendência (pontos negativos para os positivos) de aproximação dos marcos 1 e 4 provocando o encurtamento da asa (Figuras 8A e 8B). Em PC2, há clara tendência de alargamento na parte mediana da asa para os valores positivos desse componente principal. O marco 1 apresenta tendência ao encurtamento ficando mais próximo dos marcos 2 e 6 . Além disso, o marco 5 sofre acentuado deslocamento contribuindo também para o alargamento da asa na parte positiva do eixo (Figuras $8 \mathrm{C}$ e $8 \mathrm{D}$ ). $\mathrm{O}$ componente principal 3 não foi muito útil para separação dos indivíduos, pois apresentou baixa variabilidade. 

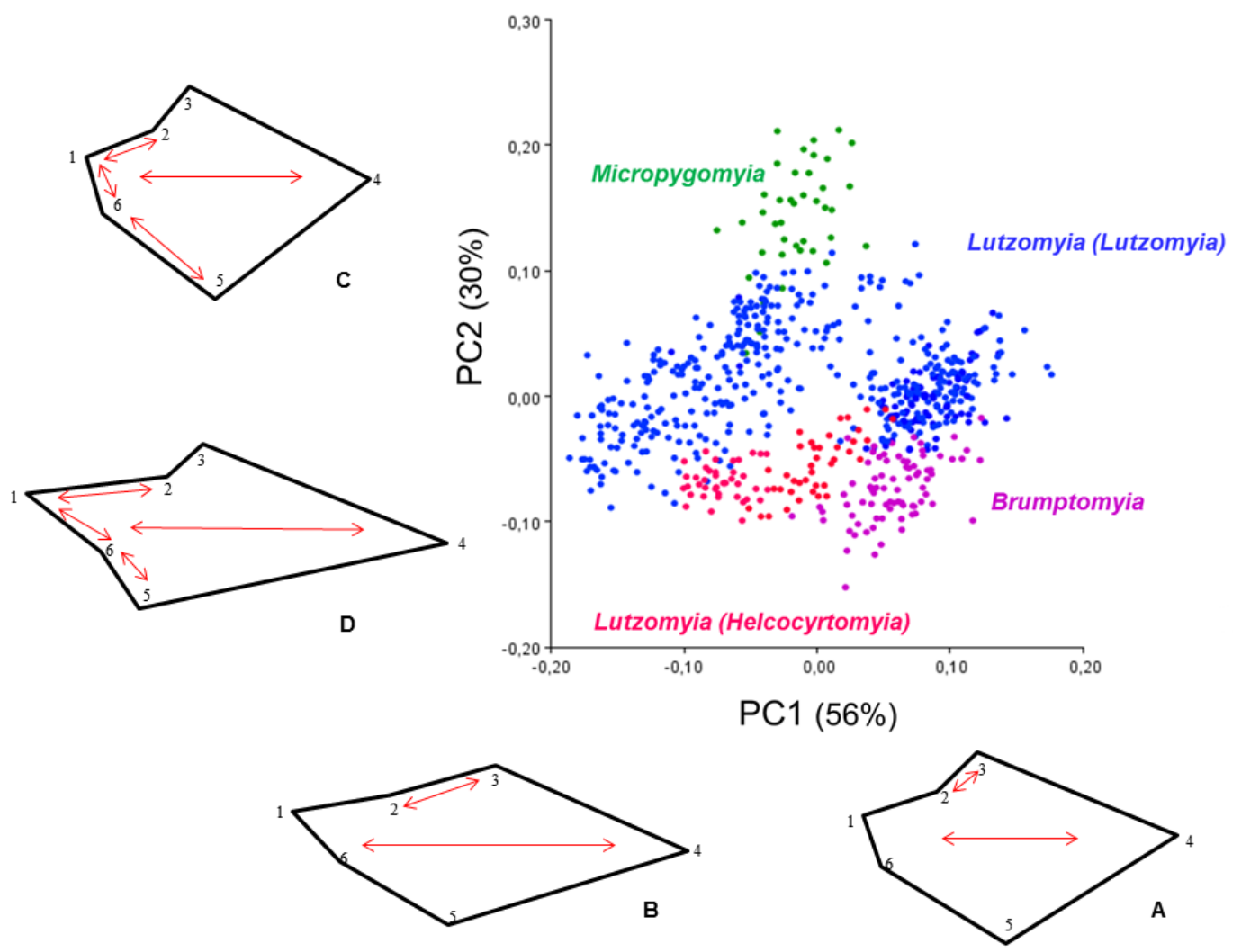

Figura 7. Análise dos componentes principais que apresentaram maior variação. Gráfico mostra a distribuição dos gêneros e dos subgêneros de Lutzomyia pesquisados quando analisados PC1 e PC2. A contribuição percentual de cada componente para a variação total de forma é apresentada entre parênteses. As modificações nas formas das asas estão representadas por A (valores positivos) e B (valores negativos)

Na Análise de Funções Discriminantes com todas as espécies houve clara separação dos gêneros tanto para machos quanto para fêmeas. Foi possível observar também diferença entre os subgêneros Lutzomyia e Helcocyrtomyia. No subgênero Lutzomyia ficou evidente a separação entre dois grupos que foram identificados como 1 e 2 sendo o primeiro composto por Lu. ischnacantha, Lu. cavernicola, Lu. almerioi, Lu. forattinii, Lu. renei e Lu. battistinii e o segundo por Lu. alencari, Lu. ischyracantha, Lu. cruzi, Lu. longipalpis, Lu. gaminarai e Lu. lichyi (Figura 8). 
A

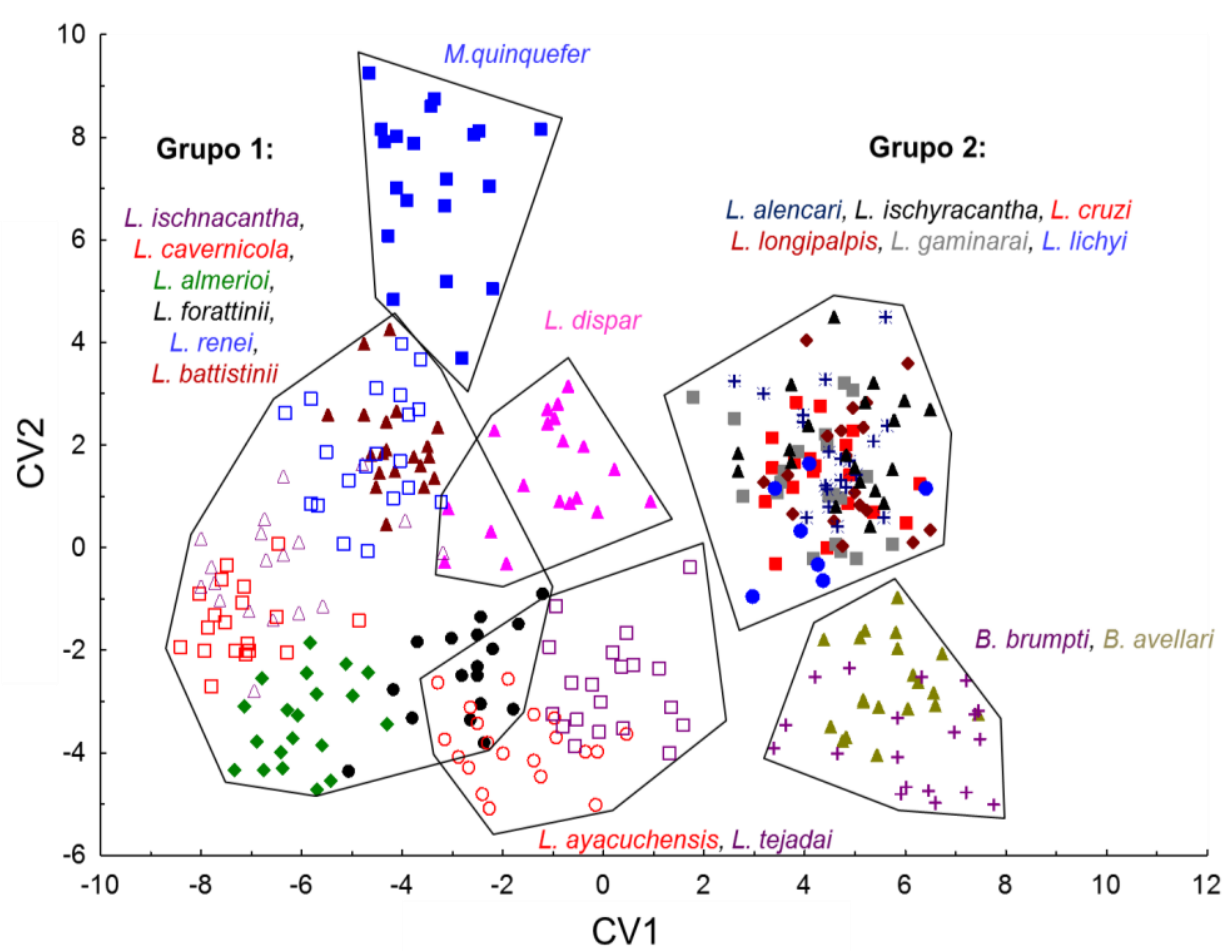

B

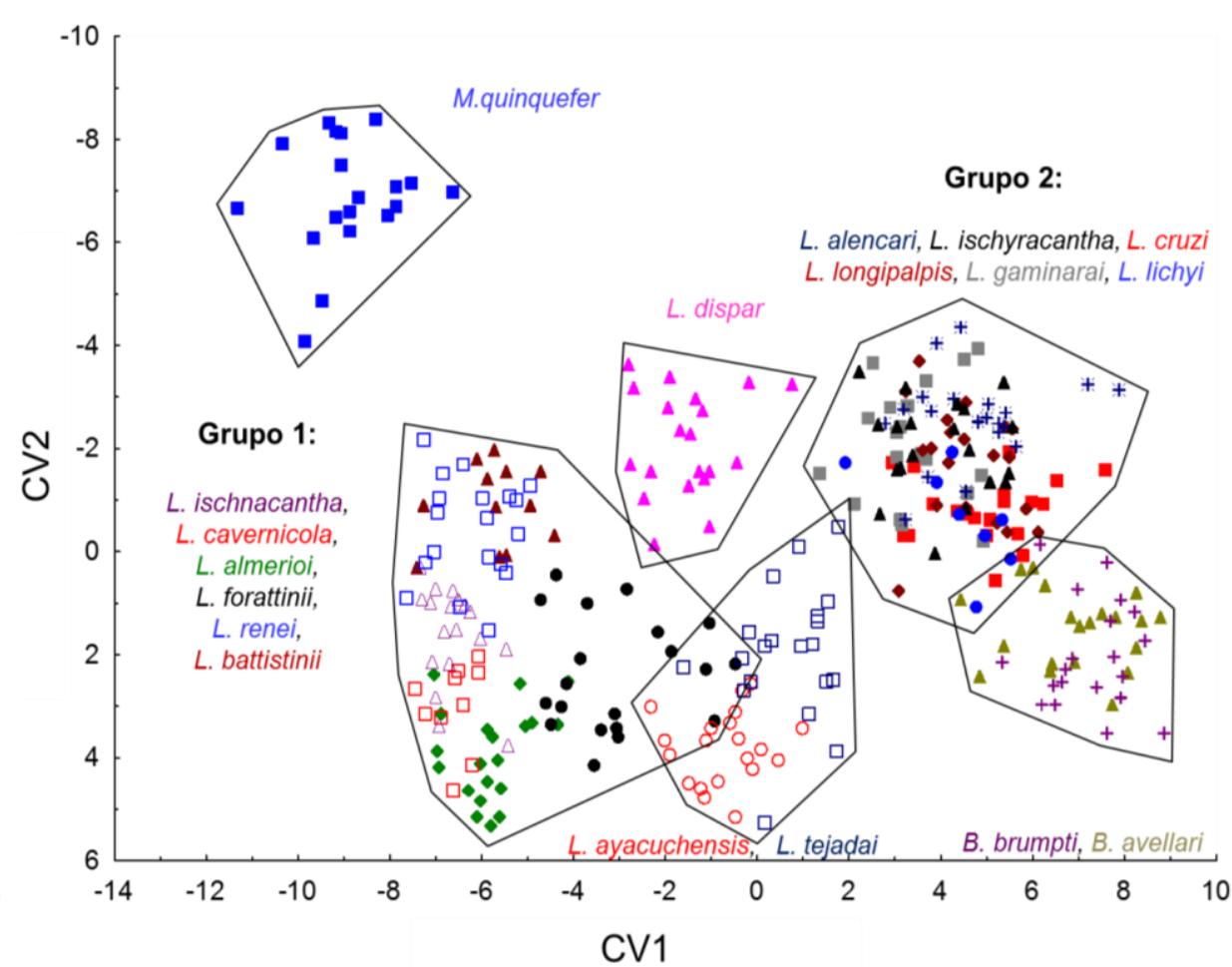

Figura 8. Mapas fatoriais baseados nos dois fatores discriminantes da variação de forma de asas (CV1 e CV2), mostrando os agrupamentos formados em "A" para as fêmeas e em "B” para os machos. Os polígonos foram traçados para facilitar a visualização dos grupos. 
Foram realizadas análises específicas para machos e fêmeas dos Grupos 1 e 2 formados no subgênero Lutzomyia. Observou-se que no Grupo 1 foi possível separar mais claramente as espécies do subgênero, no entanto ocorreram sobreposições de espécies principalmente entre Lu. renei e Lu. battistinii (Figura 9).
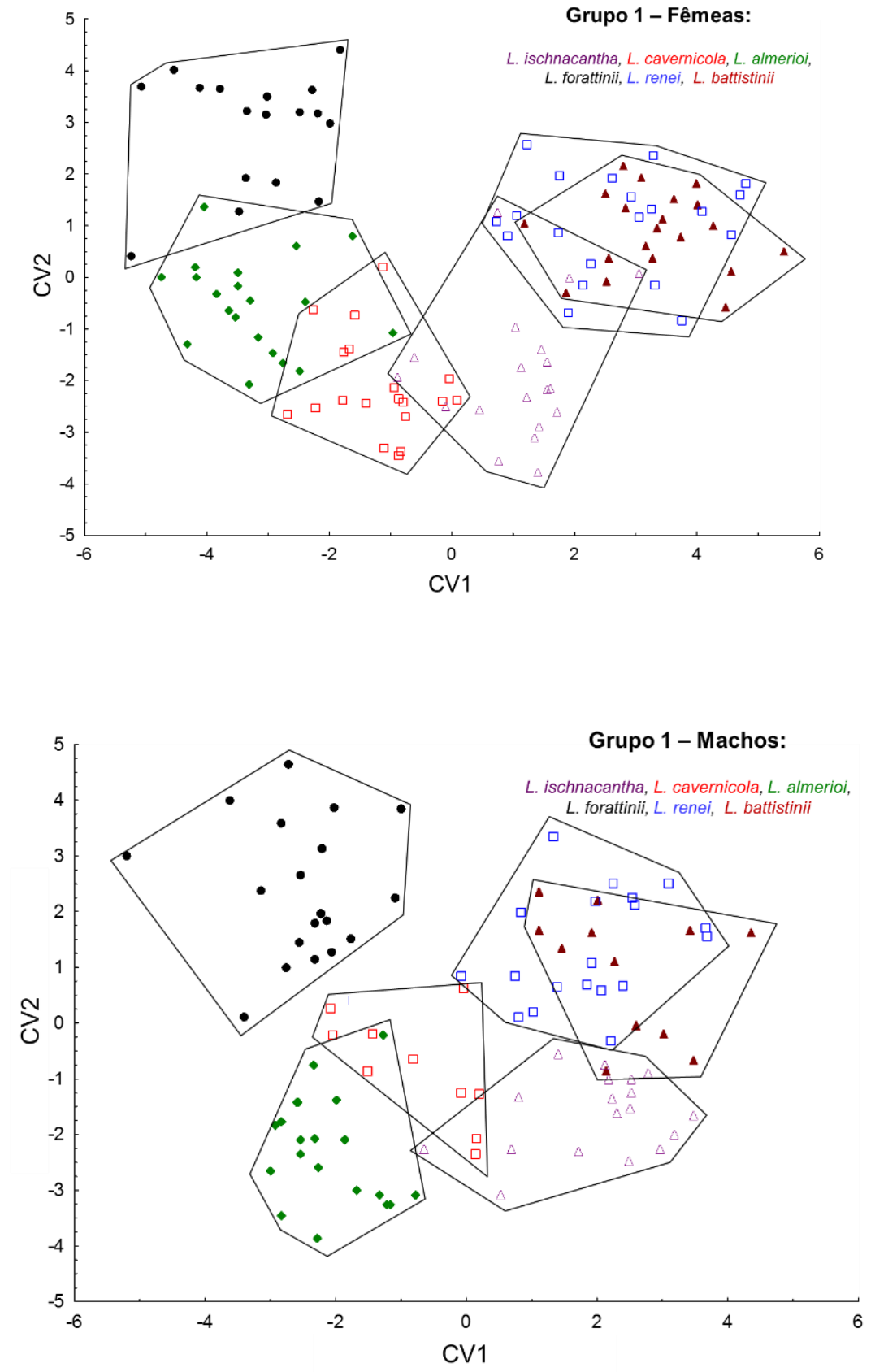

Figura 9. Mapas fatoriais baseados nos dois fatores discriminantes da variação de forma de asas (CV1 e CV2), mostrando os agrupamentos formados para as fêmeas e machos do Grupo 1 do subgênero Lutzomyia. Os polígonos foram traçados para facilitar a visualização dos grupos. 
$\mathrm{Na}$ análise do Grupo 2, tanto para as fêmeas quanto para os machos, não foi possível separar as espécies (Figura 10). Mesmo utilizando 10 landmarks, ao invés de seis, em uma análise posterior somente $\mathrm{Lu}$. lichyi foi separada das demais (Figura 11).
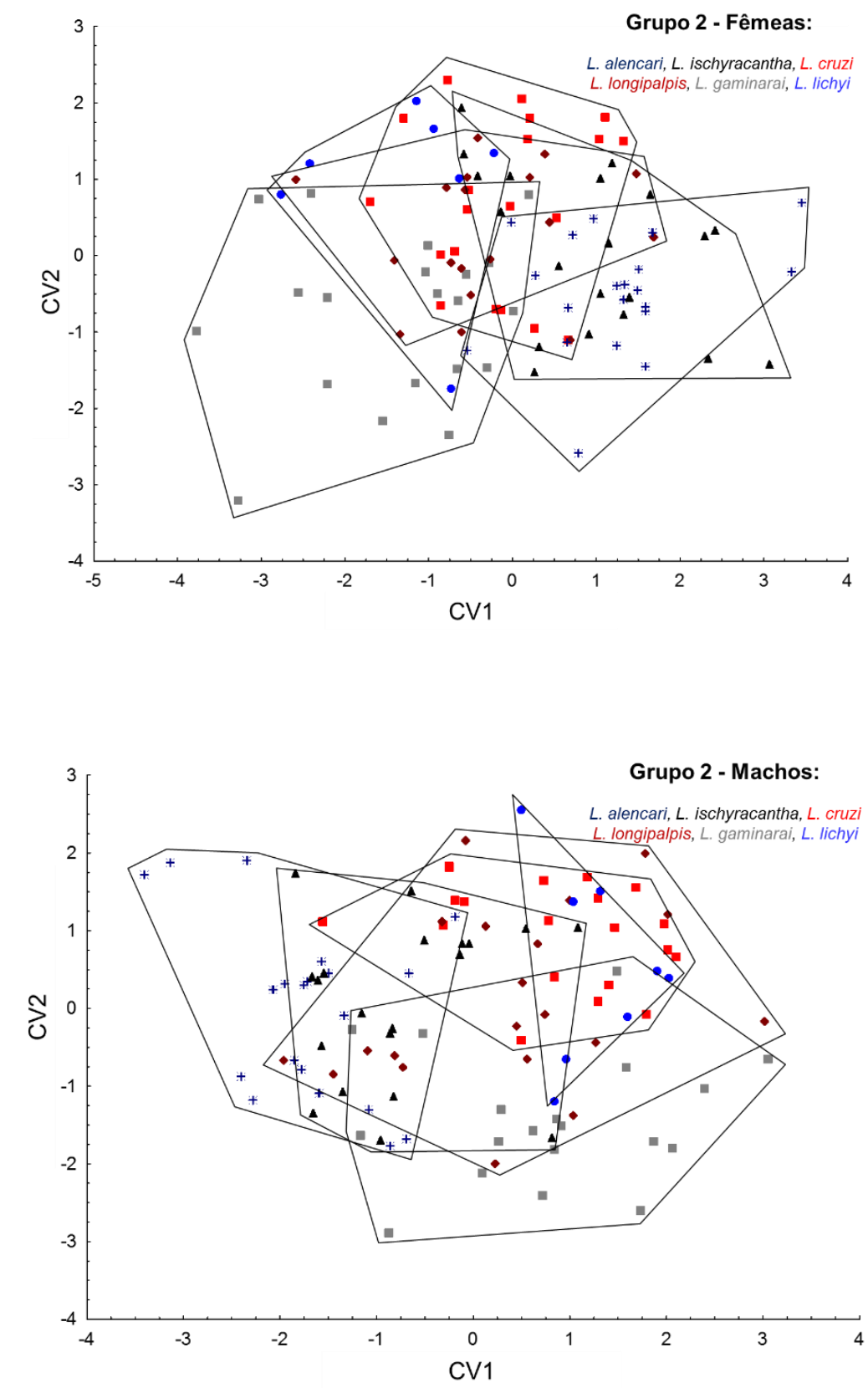

Figura 10. Mapas fatoriais baseados nos dois fatores discriminantes da variação de forma de asas (CV1 e CV2), mostrando os agrupamentos formados para as fêmeas e machos do Grupo 2 do subgênero Lutzomyia. Os polígonos foram traçados para facilitar a visualização dos grupos. 

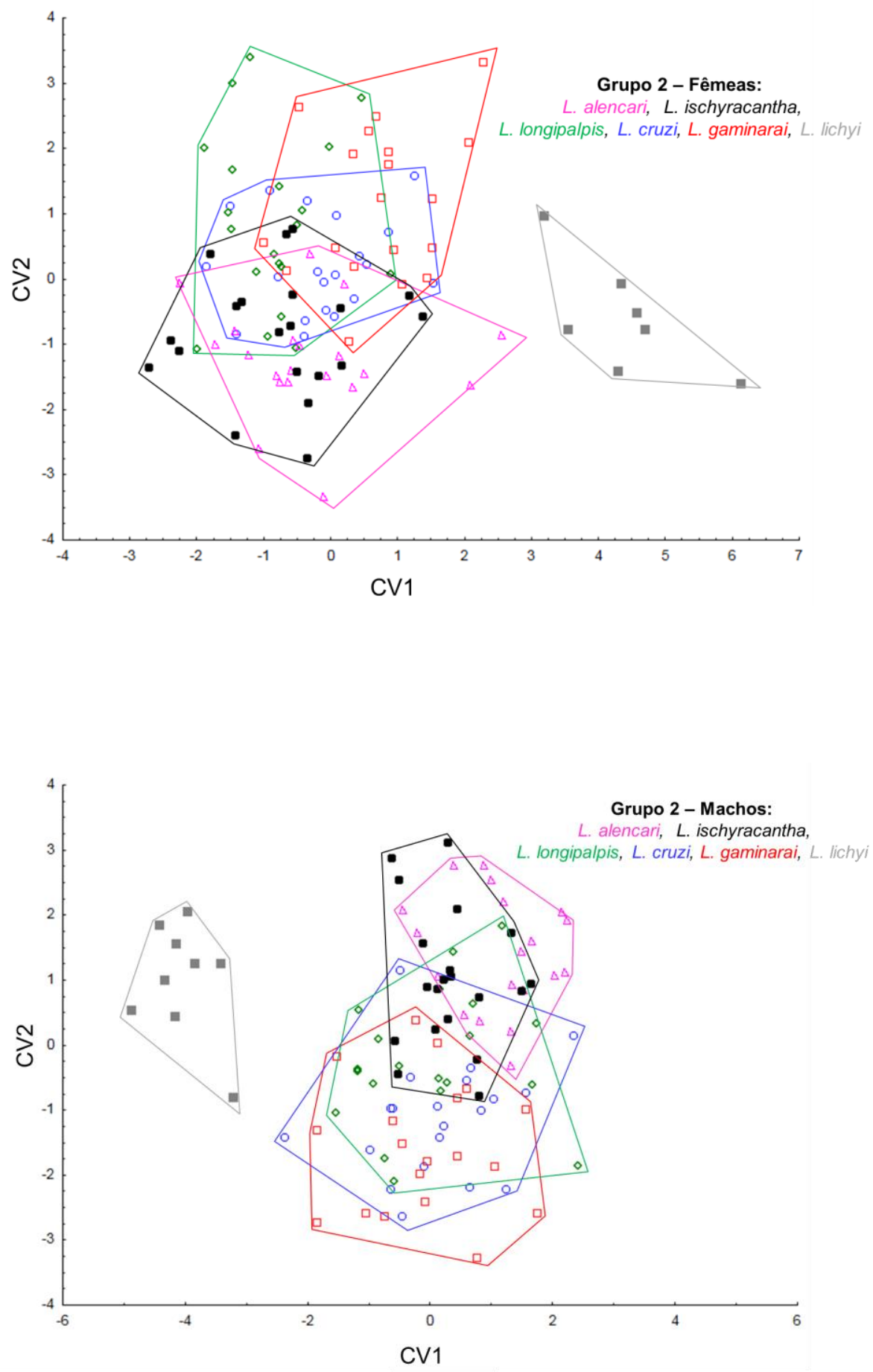

Figura 11. Mapas fatoriais baseados nos dois fatores discriminantes da variação de forma de asas (CV1 e CV2), mostrando os agrupamentos formados para as fêmeas e machos do Grupo 2 do subgênero Lutzomyia, considerando 10 marcos anatômicos. Os polígonos foram traçados para facilitar a visualização dos grupos. 
As espécies Lu. tejadai e Lu. ayacuchensis do subgênero Helcocyrtomyia formaram agrupamentos distintos após uma análise específica incluindo $L u$. forattinii, a espécie do subgênero Lutzomyia que ficou mais próxima nas análises (Figura 12).
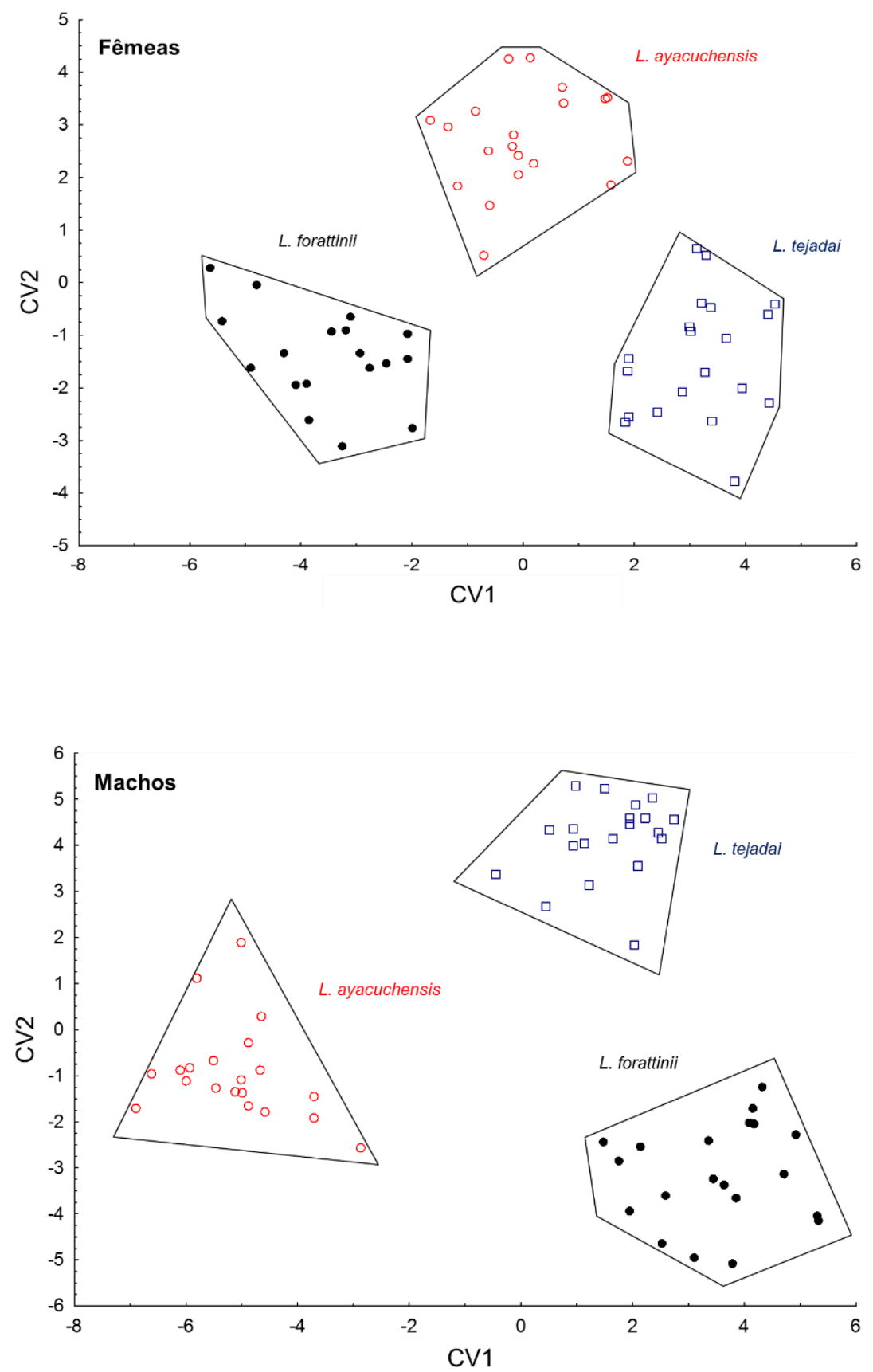

Figura 12. Mapas fatoriais baseados nos dois fatores discriminantes da variação de forma de asas (CV1 e CV2), mostrando os agrupamentos formados pelas espécies do subgênero Helcocyrtomyia incluindo Lu. forattinii para fêmeas e machos. Os polígonos foram traçados para facilitar a visualização dos grupos. 
Os sucessos de reclassificação após análise de discriminantes considerando as 18 espécies foram de 79,65\% para as fêmeas e 78,53\% para os machos. Foram feitas análises específicas de reclassificação para os agrupamentos formados. Para o subgênero Lutzomyia foram feitas duas análises sendo uma para o Grupo 1 representado por Lu. ischnacantha, Lu. cavernicola, Lu. almerioi, Lu. forattinii, Lu. renei e Lu. battistinii onde a porcentagem de reclassificações corretas para as fêmeas foi de $89,57 \%$ e para os machos foi de $91,00 \%$ com o valor Kappa de concordância de 0,91 e 0,90 respectivamente, sendo considerados muito altos (Tabela 4). A outra análise foi feita para o Grupo 2 desse mesmo subgênero representado por Lu. alencari, Lu. ischyracantha, Lu. cruzi, Lu. longipalpis, Lu. gaminarai e Lu. lichyi onde a porcentagem de reclassificações corretas foi de $55,24 \%$ para fêmeas e 58,88\% para os machos com o valor Kappa de 0,42 e 0,48 respectivamente, sendo considerados moderados (Tabela 5).

Além dessas, foram feitas duas outras análises sendo uma para as espécies do subgênero Helcocyrtomyia incluindo Lu. forattinii, a espécie do subgênero Lutzomyia que ficou mais próxima nas análises resultando em uma porcentagem de reclassificações corretas de $100 \%$ tanto para machos quanto para as fêmeas. Por fim, uma última análise incluindo o gênero Brumptomyia mostrou porcentagem de reclassificações corretas de 87,50\% e valor Kappa de 0,75 para as fêmeas.. A porcentagem de reclassificações corretas para machos foi de 67,50\% gerando um Kappa de 0,35, considerado imparcial (Tabela 6).

Não foram observados grandes efeitos alométricos nas análises de regressão entre as variáveis de forma e o TC mostrando que houve uma pequena influência do tamanho na variação de forma das asas para fêmeas $\left(\mathrm{R}^{2}=0,022 ; p=0,004\right)$ e para machos $\left(\mathrm{R}^{2}=0,128 ; p<0,001\right)$. Logo, $12,8 \%$ da variação de forma das asas dos machos pode ser explicada pelo tamanho, evidenciando que o tamanho teve influência mais pronunciada nos machos do que nas fêmeas. 
Tabela 4. Porcentagem de reclassificações corretas das espécies do subgênero Lutzomyia do Grupo 1 após a análise de discriminante com as variáveis de forma.

\begin{tabular}{|c|c|c|c|c|c|c|c|c|c|c|c|c|c|c|}
\hline \multirow[b]{2}{*}{ Espécies } & \multicolumn{6}{|c|}{ Fêmeas } & \multicolumn{8}{|c|}{ Machos } \\
\hline & LALM & LCAV & LFOR & LBAT & LCHN & LREN & $\begin{array}{c}\text { \% reclassificações } \\
\text { corretas }\end{array}$ & LALM & LCAV & LFOR & LBAT & LCHN & LREN & $\begin{array}{c}\text { \% reclassificações } \\
\text { corretas }\end{array}$ \\
\hline LALM & 17 & 2 & 1 & 0 & 0 & 0 & 85,00 & 19 & 1 & 0 & 0 & 0 & 0 & 95,00 \\
\hline LCAV & 0 & 19 & 0 & 0 & 0 & 0 & 100,00 & 0 & 9 & 0 & 0 & 1 & 0 & 90,00 \\
\hline LFOR & 1 & 0 & 16 & 0 & 0 & 0 & 94,11 & 0 & 0 & 20 & 0 & 0 & 0 & 100,00 \\
\hline LBAT & 0 & 0 & 0 & 19 & 0 & 1 & 95,00 & 0 & 0 & 0 & 9 & 2 & 1 & 75,00 \\
\hline LCHN & 0 & 1 & 0 & 2 & 16 & 0 & 84,21 & 1 & 0 & 0 & 0 & 17 & 0 & 94,44 \\
\hline LREN & 0 & 0 & 0 & 4 & 0 & 16 & 80,00 & 0 & 1 & 0 & 2 & 0 & 17 & 85,00 \\
\hline \multicolumn{9}{|c|}{ Карра $=0,91$} & \multicolumn{6}{|c|}{ Kappa $=0,90$} \\
\hline
\end{tabular}


Tabela 5. Porcentagem de reclassificações corretas das espécies do subgênero Lutzomyia do Grupo 2 após a análise de discriminante com as variáveis de forma.

\begin{tabular}{|c|c|c|c|c|c|c|c|c|c|c|c|c|c|c|}
\hline \multirow[b]{2}{*}{ Espécies } & \multicolumn{6}{|c|}{ Fêmeas } & \multicolumn{8}{|c|}{ Machos } \\
\hline & LCRU & LGAM & LLON & LALE & LCHY & LLIC & $\begin{array}{c}\text { \% reclassificações } \\
\text { corretas }\end{array}$ & LCRU & LGAM & LLON & LALE & LCHY & LLIC & $\begin{array}{c}\text { \% reclassificações } \\
\text { corretas }\end{array}$ \\
\hline LCRU & 10 & 2 & 2 & 2 & 3 & 1 & 50,00 & 14 & 0 & 3 & 1 & 1 & 1 & 70,00 \\
\hline LGAM & 2 & 16 & 0 & 1 & 1 & 0 & 80,00 & 1 & 14 & 1 & 1 & 2 & 0 & 73,68 \\
\hline LLON & 5 & 2 & 7 & 0 & 4 & 0 & 38,89 & 4 & 2 & 7 & 4 & 1 & 2 & 35,00 \\
\hline LALE & 1 & 1 & 0 & 15 & 3 & 0 & 75,00 & 0 & 2 & 0 & 14 & 4 & 0 & 70,00 \\
\hline LCHY & 3 & 0 & 2 & 6 & 8 & 1 & 40,00 & 2 & 1 & 2 & 4 & 11 & 0 & 55,00 \\
\hline LLIC & 3 & 1 & 1 & 0 & 0 & 2 & 28,57 & 3 & 2 & 0 & 0 & 0 & 3 & 37,50 \\
\hline \multicolumn{9}{|c|}{ Kappa $=0,42$} & \multicolumn{6}{|c|}{ Карpa $=0,48$} \\
\hline
\end{tabular}


Tabela 6. Porcentagem de reclassificações corretas das espécies do gênero Brumptomyia após a análise de discriminante com as variáveis de forma.

\begin{tabular}{|c|c|c|c|c|c|c|}
\hline \multirow[b]{2}{*}{ Espécies } & \multicolumn{3}{|r|}{ Fêmeas } & \multicolumn{3}{|r|}{ Machos } \\
\hline & BAVE & BBRU & $\%$ reclassificações corretas & BAVE & BBRU & $\%$ reclassificações corretas \\
\hline BAVE & 18 & 2 & 90,00 & 13 & 7 & 65,0 \\
\hline \multirow[t]{2}{*}{ BBRU } & 3 & 17 & 85,00 & 6 & 14 & 70,0 \\
\hline & \multicolumn{3}{|c|}{ Карра $=0,75$} & \multicolumn{3}{|c|}{ Kappa $=0,35$} \\
\hline
\end{tabular}

Foi realizada uma Análise de Agrupamento para elaboração de dendrogramas derivados das distâncias de Mahalanobis que podem ser obtidas a partir da distância entre as formas médias dos grupos. Dessa forma foi possível comparar os agrupamentos resultantes da morfometria geométrica de asas com os propostos por Galati (2003).

Essa análise foi realizada para as espécies subgênero Lutzomyia resultando na formação de dois grupos tanto para machos quanto para fêmeas assim como na classificação de Galati (2003). De forma geral, houve concordância na composição dos grupos ao comparar as características de forma das asas, com exceção de Lu. ischnacantha para os machos (Figura 13). Entretanto, essa concordância foi menor para as fêmeas (Figura 14), em que Lu. almerioi, Lu. forattini, Lu. lichyi e Lu. dispar foram posicionadas em grupos diferentes. 


\section{Machos}

A

Galati (2003)

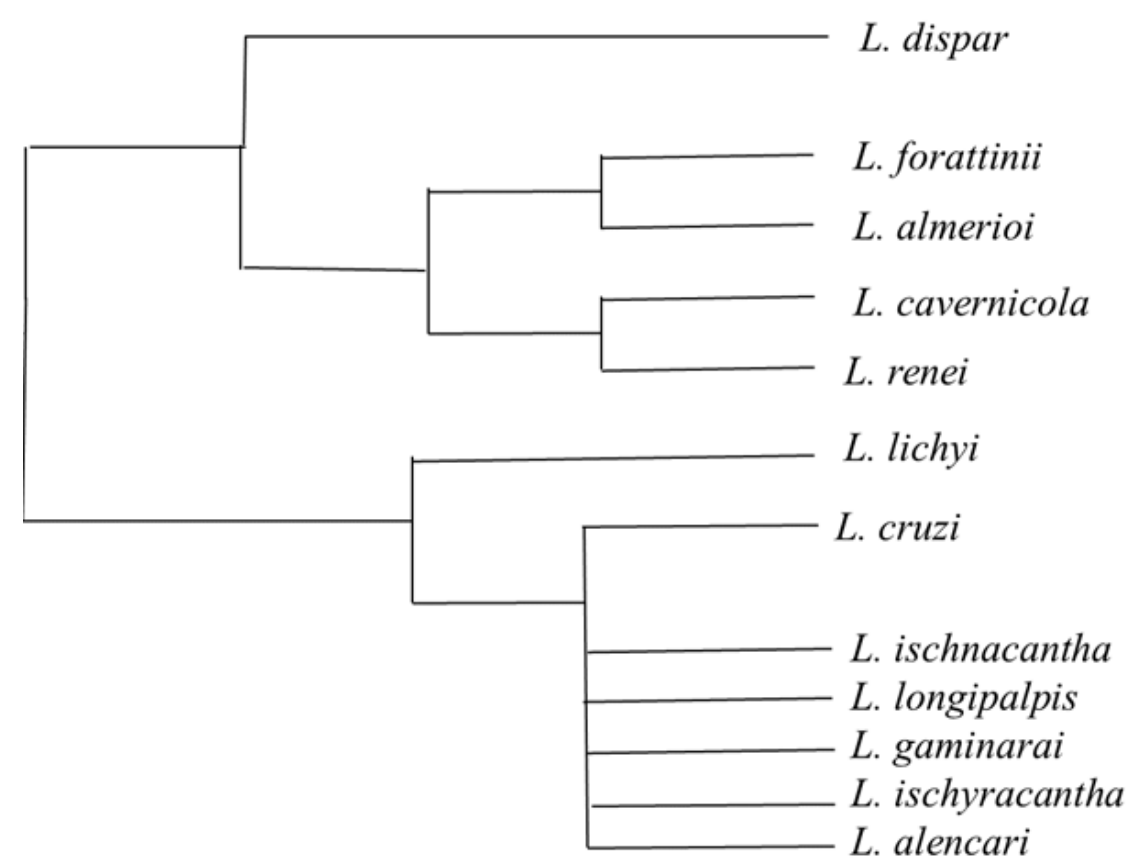

B

Morfometria geométrica de asas

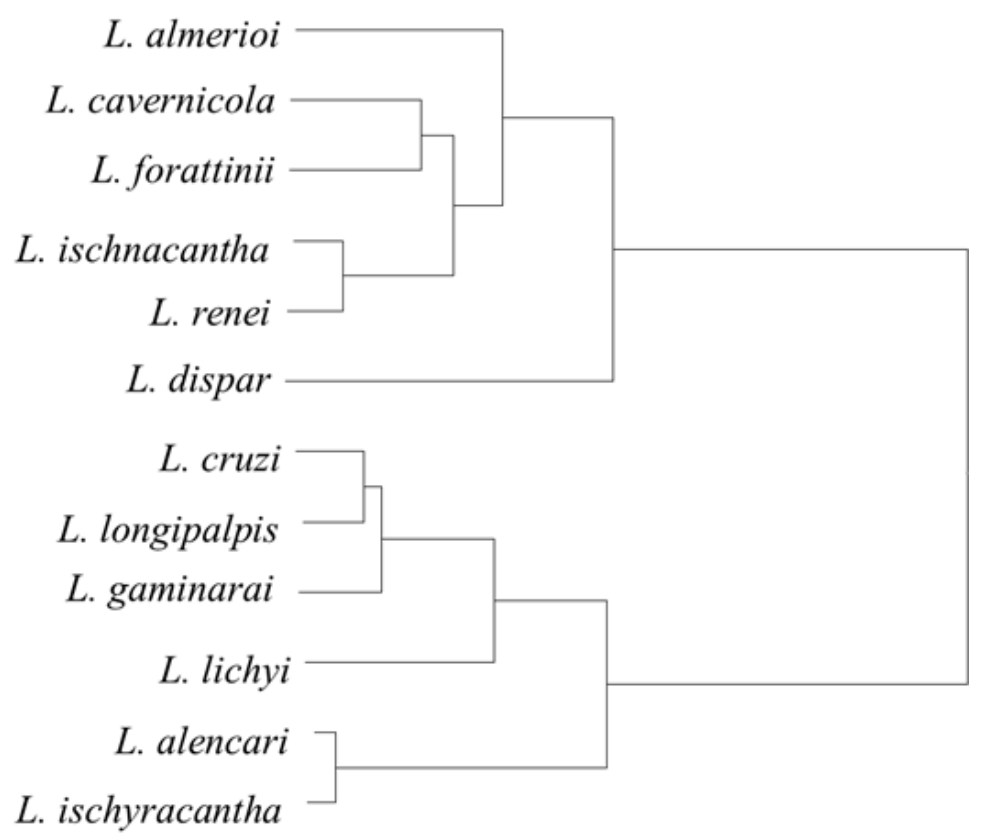

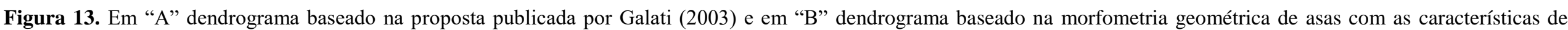

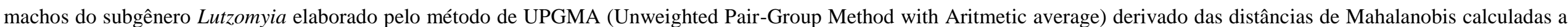
partir das variáveis de forma. 


\section{Fêmeas}

A

Galati (2003)

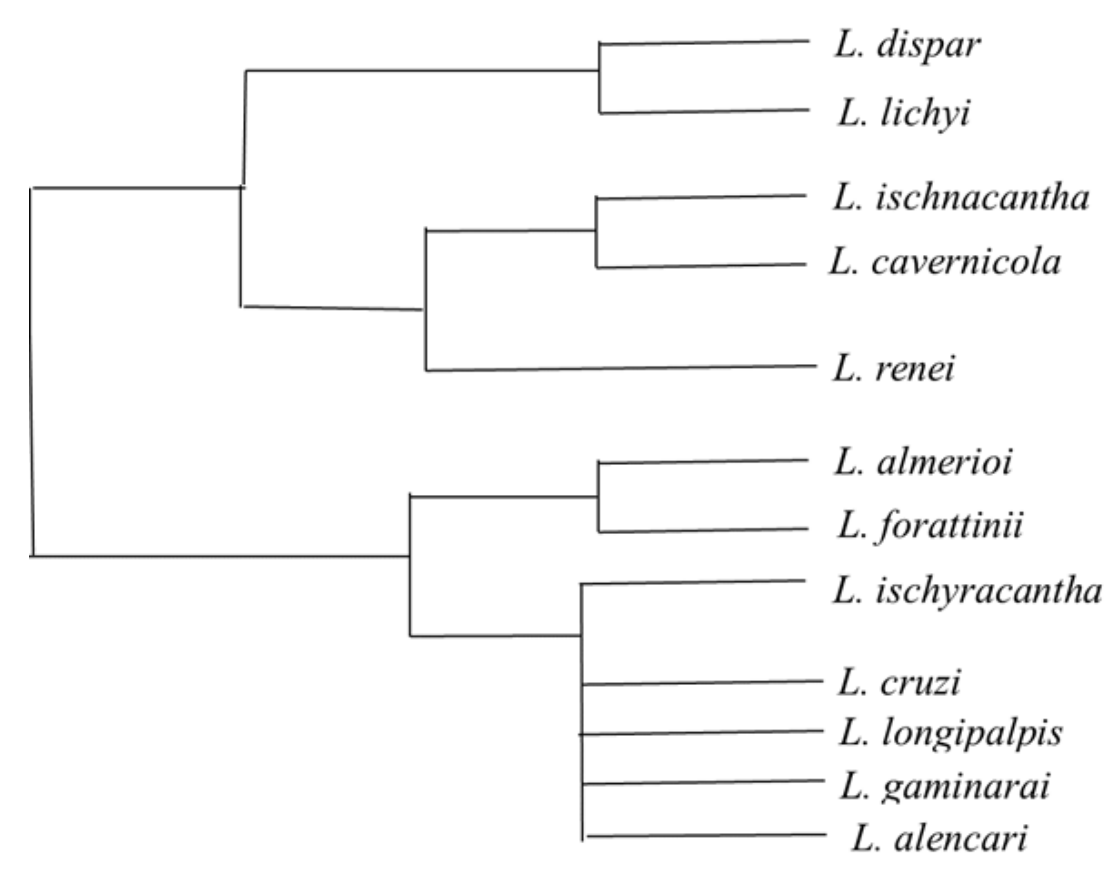

Morfometria geométrica de asas

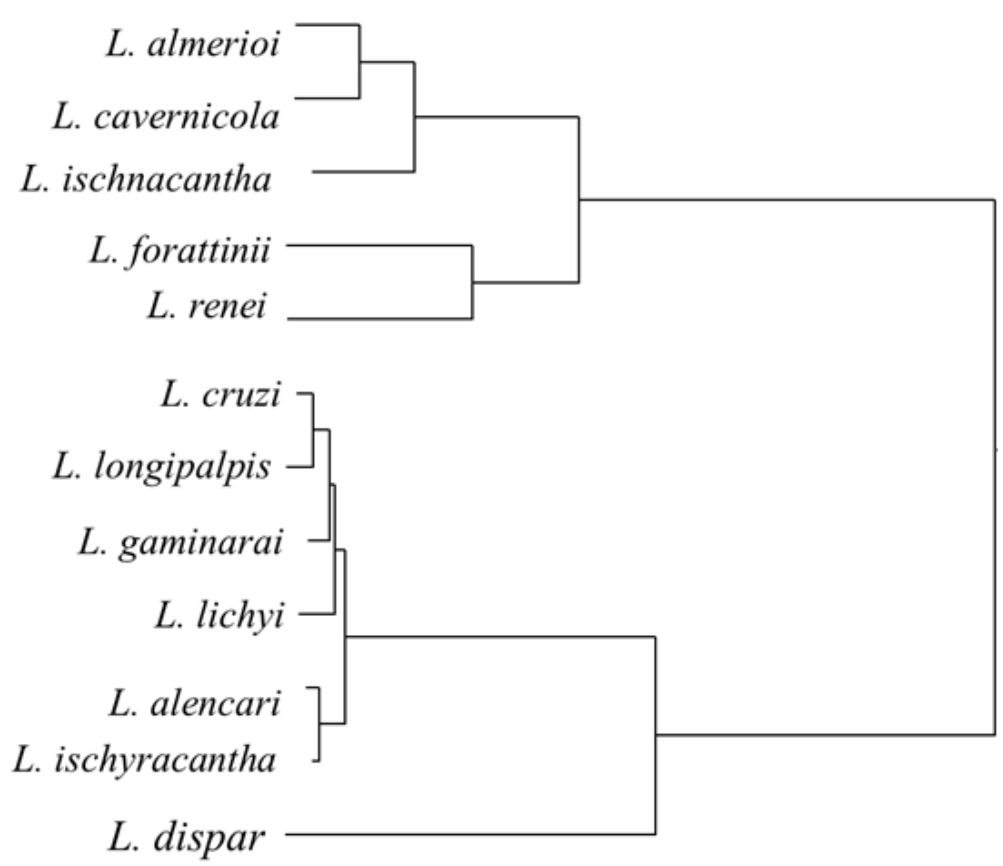

Figura 14. Em "A" dendrograma baseado na proposta publicada por Galati (2003) e em "B" dendrograma baseado na morfometria geométrica de asas com as características de fêmeas do subgênero Lutzomyia elaborado pelo método de UPGMA (Unweighted Pair-Group Method with Aritmetic average) derivado das distâncias de Mahalanobis calculadas a partir das variáveis de forma. 


\section{DISCUSSÃO}

O presente estudo mostrou significativa variação de tamanho e forma das asas de Lutzomyia (Lutzomyia) (sensu Galati 2003) em comparação com outros subgêneros e gêneros de flebotomíneos analisados. Considerando somente o subgênero Lutzomyia a morfometria alar diferenciou dois grupos; os valores de reclassificação correta das espécies do Grupo 1 ( $L u$. ischnacantha, Lu. cavernicola, Lu. almerioi, Lu. forattinii, Lu. renei e Lu. battistinii) foram muito altos. No entanto, as espécies do Grupo 2, incluindo as fêmeas indistinguíveis de Lu. cruzi, Lu. longipalpis e Lu. gaminarai não puderam ser diferenciadas por morfometria alar, mesmo utilizado maior número de marcos anatômicos. Finalmente, os agrupamentos gerados nas análises foram semelhantes aos propostos por Galati (2003), principalmente para os machos.

A morfometria geométrica, apesar de ser uma técnica relativamente recente, tem sido aplicada ao estudo de diversos grupos, incluindo insetos de importância em Saúde Pública (Dujardin \& Slice, 2007). Os flebotomíneos representam um grupo de insetos com alguns problemas taxonômicos como o caso do subgênero Lutzomyia e suas espécies crípticas (Bauzer et al., 2007). Tendo em vista que a resolução desses problemas tem importantes implicações epidemiológicas, o presente estudo trouxe contribuições para diferenciação das espécies desse subgênero.

Os caracteres morfométricos podem ser analisados quanto ao tamanho e quanto à forma. Estes possuem duas fontes principais de variação, sendo uma de origem ambiental - principalmente relacionada ao tamanho - e outra de origem genética - principalmente relacionada à forma (Baylac et al., 2003; Dujardin, 2008; Gurgel-Gonçalves et al., 2008).

A variação de tamanho da asa das espécies foi analisada sob duas perspectivas: interespecífica e intraespecífica. Os resultados mostraram que houve diferença significativa de tamanho entre as espécies das duas coleções pesquisadas. Comparando o tamanho do centróide foi constatado que $L u$. dispar possui a asa menor e Br. brumpti a asa maior, o que parece indicar uma correlação do tamanho da asa com o tamanho do corpo do inseto, sendo as asas de Brumptomyia notoriamente maiores que as demais.

Vários estudos têm mostrado influência de fatores ambientais no tamanho de insetos, como por exemplo, temperatura (Smith \& Mullens, 2003), dieta ou densidade larval (Jirakanjanakit et al., 2007) e habitat de origem (Dujardin et al., 1997a, 1999c; Gurgel-Gonçalves et al., 2011). Portanto, 
essa variação deve ser avaliada com cuidado, visto que o tamanho pode ser influenciado pela heterogeneidade ambiental nem sempre podendo ser empregado como um caracter discriminante (Calle et al., 2008). No entanto, modificações interespecíficas de tamanho devem ter maior relação com variação genotípica, considerando que existe uma base genética para explicar tamanho de uma asa (Birdsall et al., 2000; Dujardin \& Slice, 2007). Isso poderia explicar, por exemplo, as variações de tamanho entre asas de flebotomíneos dos gêneros como Brumptomyia e Lutzomyia encontradas no presente estudo.

Com relação à análise intraespecífica de tamanho, foi encontrado dimorfismo sexual no qual as asas das fêmeas foram maiores que as dos machos para quase todas as espécies estudadas, exceto Lu. longipalpis, Lu. alencari, Lu. ischyracantha, Lu. lichyi e Mi. quinquefer que não apresentaram diferença significativa entre os sexos. Esses resultados demonstram que as modificações nas asas de machos e fêmeas são influenciadas por diferentes fatores como já evidenciado por outros estudos envolvendo mosquitos (Devicari et al., 2011; Vidal et al., 2011; 2012) e triatomíneos (Dujardin et al., 1999c). É provável que asas de machos e fêmeas do subgênero Lutzomyia sigam por diferentes padrões evolutivos já que cada sexo assume um papel particular dentro da sua espécie. Comportamentos diferenciados entre os sexos como os de corte e alimentação (as fêmeas são hematófagas), por exemplo, poderiam resultar em pressões seletivas diferenciadas para machos e fêmeas, o que explicaria o maior tamanho das asas das fêmeas na maioria das espécies. Logo, segundo Vidal e colaboradores (2012), não se pode descartar a ação da seleção sexual nesse cenário.

A ausência de dimorfismo sexual relacionado ao tamanho em algumas espécies como $L u$. longipalpis poderia ser resultante de processos adaptativos. Para alguns grupos de insetos vetores como os triatomíneos é evidente a diminuição do dimorfismo sexual durante a transição do ambiente silvestre para o urbano - laboratório ou casas (Dujardin et al., 1999c; Gurgel-Gonçalves et al., 2011). Esse fato poderia explicar porque machos e fêmeas de Lu. longipalpis apresentaram tamanho similar, porém merece um estudo mais detalhado comparando populações silvestres e domiciliadas.

Como já mencionado, os padrões de forma estão mais relacionados com as variações genotípicas. Alguns estudos comparando morfometria alar com dados genéticos demonstram que há concordância entre as filogenias (Moraes et al., 2004; Klingenberg \& Gidaszewski, 2010; MuñozMuñoz et al., 2011), evidenciando a existência de um sinal filogenético relacionado a forma das asas. Logo, essa variação pode ser empregada com maior confiança para a distinção entre espécies, 
principalmente, se elas forem crípticas. Nesse caso, muitas vezes as diferenças são tão sutis que não podem ser detectadas pela morfologia ou morfometria tradicional. Portanto, quantificar essa variação de forma pode ajudar na solução de problemas taxonômicos (Dujardin, 2008; GurgelGonçalves et al., 2008).

Todavia, é preciso observar que as modificações de forma (em menor grau que as de tamanho) também podem ser influenciadas por variações ambientais como, por exemplo, a altitude (Dujardin \& Le Pont, 2004). Então, algumas mudanças ambientais também podem influenciar na conformação desses insetos devendo ser levadas em conta quando se utiliza morfometria para identificação de flebotomíneos.

No presente estudo a morfometria de asas permitiu discriminar espécies de diferentes gêneros e subgêneros, concordando com estudos anteriores (e.g. Cazorla \& Acosta 2003; Cazorla, 2009). Godoy et al. (2014) realizaram um trabalho análogo ao apresentado aqui e, para ambos os estudos, as asas de Brumptomyia foram maiores e com formato mais curto quando comparadas com as dos outros gêneros. Por outro lado, as asas de Lutzomyia, Nyssomyia e Micropygomyia apresentaram forma mais alongada o que pode estar relacionado com diferentes capacidades de voo. Futuros estudos comparando resultados de atividade de voo medida por estudos bioquímicos (Soares \& Santoro, 2000) e de desempenho (Killick-Kendrick et al., 1986) com resultados de morfometria geométrica de asas poderão elucidar as diferenças observadas e ainda contribuir para entender o comportamento de flebotomíneos.

Além disso, ao analisar as modificações na forma das asas nos componentes principais foi possível detectar os pontos onde ocorreu maior variação sendo os mais importantes para separação dos gêneros e subgêneros. É importante destacar que esses pontos de maior variação também foram muito similares aos encontrados por Godoy et al. (2014) sendo eles, os marcos anatômicos encontrados nas seguintes posições da asa: para PC1 marco localizado no ápice de R1; para PC2 marcos localizados na bifurcação R2+3+4, ápice de R5 e ápice de M4. Esses são resultados relevantes para futuros trabalhos desenvolvidos nessa área. Ainda ficou claro que os valores negativos de ambos componentes principais estão associados às formas mais alongadas das asas.

Posteriormente, a Análise de Funções Discriminantes reforçou a separação dos gêneros e subgêneros. Observando os mapas fatoriais gerados para machos e fêmeas é possível notar que as modificações nas formas das asas seguem um padrão similar para os dois sexos diferentemente do que ocorreu para o tamanho. O que parece mais uma vez reforçar a forma como resultante da variação genética e o tamanho com resultante da variação ambiental. 
No subgênero Lutzomyia houve a formação de dois grupos distintos. No Grupo 1 as espécies Lu. ischnacantha, Lu. cavernicola, Lu. almerioi, Lu. forattinii, Lu. renei e Lu. battistinii foram melhor diferenciadas ocorrendo sobreposições mais evidentes apenas entre Lu. renei e Lu. battistinii indicando que a forma da asa dessas duas espécies foi mais similar com relação as das outras espécies. No entanto, para o Grupo 2 composto por Lu. alencari, Lu. ischyracantha, Lu. cruzi, Lu. longipalpis, Lu. gaminarai e Lu. lichyi, diferente do observado em outros estudos (Dujardin et al., 1999b; Dujardin \& Le Ponte, 2000), não foi possível separar as espécies nem mesmo aumentando para 10 a quantidade de marcos anatômicos.

O resultado obtido para o Grupo 2 muito provavelmente está relacionado a existência do "complexo Lutzomyia longipalpis" que vem sendo amplamente estudado desde o primeiro trabalho abordando essa questão publicado por Mangabeira (1969). Esse tema ainda é bastante discutido na literatura em várias pesquisas com análises genéticas, morfológicas, de isoenzimas, moleculares, bioquímicas e estudos sobre acasalamento. Sendo que, alguns apoiam a existência desse complexo (e.g. Ward et al., 1983, 1985; Yin et al., 1999; Souza et al., 2004; Bauzer et al., 2002; Maingon et al., 2003; Bottecchia et al., 2004; Hamilton et al., 2005; Pinto et al., 2015; Santos et al., 2015) e outros não concordam com sua existência (e.g. Mukhopadhyay et al., 1998; Mutebi et al., 1999; Azevedo et al., 2000; Arrivillaga et al., 2002; Balbino et al., 2006).

No entanto, Bauzer et al. (2007) em sua revisão sobre o "complexo Lutzomyia longipalpis" propuseram que as evidências levantadas até o momento já são suficientes para comprovar a existência do complexo e apontam ainda, possíveis razões para as inconsistências entre marcadores diferentes: especiação recente mantendo polimorfismos ancestrais; alguns marcadores poderiam ter taxas de evolução mais lentas; ocorrência de introgressão relacionada com um isolamento reprodutivo incompleto. Logo, a dificuldade para solução dessa questão e, por sua vez a separação das espécies do Grupo 2, podem ser explicadas por um processo de especiação ainda incipiente com espécies que divergiram apenas recentemente. Devido a isso, ainda não há um consenso relacionado a quantas ou quais espécies pertenceriam ao "complexo Lutzomyia longipalpis".

A morfometria também vem sendo utilizada por alguns autores com objetivo de elucidar essa questão. O primeiro estudo utilizando análises morfométricas para compreender a variação dentro de Lu. longipalpis foi realizado por Dujardin et al. (1997b) que utilizaram a geometria alar dos machos para comparar populações da Bolívia, Colômbia, Brasil e Nicarágua. Como resultado das análises multivariadas, foi possível distinguir três grupos relacionados com a geografia e padrão das manchas nos tergitos. De la Riva et al. (2001) também analisaram a geometria alar de machos 
da Bolívia e Nicarágua. Os autores demonstraram a formação de dois grupos, entretanto essa variação na geometria alar de $L u$. longipalpis não mostrou grandes subdivisões geográficas nem separou caracteres ecológicos (peridomiciliar ou silvestre) ou fenotípicos (uma ou duas manchas). No presente estudo, a morfometria geométrica de asas foi realizada para diferenciação das espécies do subgênero Lutzomyia. Esse objetivo foi parcialmente atingido com as espécies do Grupo 1 porém, as fêmeas crípticas do Grupo 2 ainda permaneceram indistinguíveis. Dessa forma, haveria necessidade de quantificar a variação morfométrica de outras estruturas como espermatecas ou palpos (Dujardin et al. 1999a, Carzola \& Acosta 2003) e ainda analisar a variação genética entre essas espécies (Pinto et al. 2015). Adicionalmente, esses estudos deverão incluir diferentes populações de Lu. longipalpis considerando a grande variação fenotípica (De la Riva et al. 2001, Hamilton et al., 2005, Santos et al. 2015), e genotípica (Arrivillaga et al. 2002) nessa espécie

Esse resultado foi reforçado por uma Análise de Agrupamento utilizada para elaboração de dendrogramas a partir das distâncias de Mahalanobis na qual, também foi possível observar a formação de dois grupos para as espécies do subgênero Lutzomyia. Comparando os agrupamentos formados com a proposta filogenética de Galati (2003) constatamos que, de forma geral, houve concordância na composição e disposição dos grupos indicando que as asas dos flebotomíneos apresenta valor taxonômico. Considerando esses resultados, é importante destacar que este trabalho traz uma nova evidência confirmando a proposta de classificação de Galati (2003).

Analisando os agrupamentos mencionados acima, é possível extrair algumas informações importantes. As espécies que compõem os dois grupos são as mesmas dos grupos formados pela Análise de Funções Discriminantes, porém a Análise de Agrupamento deixa mais evidente as distâncias entre as espécies do subgênero. Foi consenso tanto para machos quanto para fêmeas que Lu. longipalpis e Lu. cruzi são espécies muito próximas formando um grupo irmão de $L u$. gaminarai. O que era esperado, pois elas são morfologicamente semelhantes.

Outros autores chegaram a essa mesma conclusão por vários métodos. Santos et al. (2015) não encontraram diferenças morfométricas significativas ao comparar populações de $L u$. longipalpis e Lu. cruzi do Mato Grosso do Sul indicando a ocorrência de introgressão entre essas duas espécies. No âmbito da genética, Pinto et al. (2015) mostraram que estas espécies são muito relacionadas apresentando baixa divergência em suas sequências genéticas o que igualmente aponta ser resultado de introgressão. Ainda foi sugerido nesse trabalho que Lu. alencari também parece fazer parte do complexo Lu. longipalpis. Estudos sobre acasalamento também confirmam a proximidade entre Lu. longipalpis e Lu. cruzi. Brazil \& Hamilton (2002) e Vigoder et al. (2010) 
evidenciaram, respectivamente, que feromônios sexuais e "lovesongs" de machos de $L u$. cruzi são similares aos produzidos por algumas populações de $\mathrm{Lu}$. longipalpis.

Com relação às limitações apresentadas no presente estudo, podemos ressaltar uma relacionada principalmente ao tamanho, que foi a utilização de equipamentos diferentes para o registro das fotos. Como foi utilizado material de coleções de referência e cada laboratório possui equipamentos de modelos distintos, não foi possível estabelecer uma padronização precisa para captura das imagens. Contudo, os resultados da alometria não evidenciaram influência significativa do tamanho sobre a forma das asas não trazendo assim, prejuízo para as análises dessa variável desenvolvidas nesse trabalho. Uma segunda limitação relacionada também à padronização é o fato de que os exemplares pesquisados já se encontravam previamente montados. No entanto, Shimabukuro et al. (2016) não encontraram diferenças estatísticas significativas entre espécimes montados em Bálsamo do Canadá e Berlese indicando que o meio não estaria influenciando nas análises. Mesmo assim, futuramente, seria interessante investigar se outros aspectos da montagem de lâminas podem influenciar de alguma maneira os resultados obtidos.

Estudos de morfometria geométrica de insetos de interesse médico devem ser ampliados devido à acessibilidade de câmeras digitais com maior resolução, técnicas de tratamento de imagem, softwares especializados na obtenção de marcos anatômicos e análise de tamanho e forma das asas (Dujardin \& Slice, 2007). Isso se faz necessário já que essa técnica tem contribuído para apoiar estudos filogenéticos de flebotomíneos.

Para esse grupo, futuros estudos poderão avaliar a forma de cabeças, espermatecas, parâmetros, asas e suas contribuições para a distinção das espécies similares. Além disso, técnicas de análise de contornos dessas estruturas (Dujardin et al., 2014) poderão ser aplicadas para ampliar o poder de discriminação das espécies crípticas de flebotomíneos. Particularmente, com relação às asas, o conjunto de imagens obtido para as análises pode ser o primeiro passo para montar uma coleção de referência de asas desses insetos, a qual poderia ser de acesso livre e utilizada por diferentes grupos de pesquisa, assim como a coleção "wingbank" em desenvolvimento para mosquitos (Virgninio \& Suesdek, 2016). Adicionalmente, essa coleção poderia servir de base para futuros estudos de identificação automatizada, os quais têm sido desenvolvidos para outros grupos de insetos como borboletas e mariposas (Mayo \& Watson, 2007; Kang et al., 2012a, b; Wang et al., 2012), abelhas (Arbuckle et al., 2001; Arbuckle, 2002; Francoy \& Imperatriz-Fonseca, 2010), formigas-leão (Yang et al., 2015) e mosquitos (Lorenz et al., 2015). 


\section{CONCLUSÕES}

- A morfometria geométrica de asas foi útil para identificar padrões morfológicos de gêneros e subgêneros de flebotomíneos;

- Há significativa variação de tamanho e forma das asas de Lutzomyia (Lutzomyia), em comparação com outros subgêneros e gêneros;

- Há dimorfismo sexual no tamanho das asas para a maioria das espécies pesquisadas;

- Notou-se dois grupos morfologicamente distintos de espécies dentro do subgênero Lutzomyia. A discriminação entre espécies dentro de um dos grupos é possível. No entanto, para o outro grupo, que inclui as fêmeas morfologicamente indistinguíveis, não foi possível identificar as espécies por geometria alar;

- As espécies vetoras de Leishmania (Leishmania) infantum, Lutzomyia longipalpis e Lutzomyia cruzi foram muito próximas nos agrupamentos gerados pela geometria alar;

- A utilização de mais marcos anatômicos não aumentou significativamente o poder de discriminação da análise;

- Os agrupamentos gerados por morfometria alar reforçam a proposta de classificação de Galati (2003). 


\section{REFERÊNCIAS BIBLIOGRÁFICAS}

Akhoundi, M., Kuhls, K., Cannet, A., Votýpka, J., Marty, P., Delaunay, P. \& Sereno, D. 2016. A Overview of the Classification, Evolution, and Dispersion of Leishmania Parasites and Sandflies. PLoS Neglected Tropical Diseases, 10(3): e0004349.

Añez, N., Valenta, D.T., Cazorla, D., Quicke, D.J. \& Fericiangeli, D., 1997. Multivariate analysis to discriminate species of phlebotomine sand flies (Diptera: Psychodidae): Lutzomyia townsendi, L. spinicrassa, and L. youngi, Journal of Medical Entomology, 34(3): 312-316.

Alvar, J., Velez, I.D., Bern, C., Herrero, M., Desjeux, P, Cano, J., Jannin, J. \& den Boer, M. 2012. Leishmaniasis Worldwide and Global Estimates of Its Incidence. PLoS ONE, 7(5): e35671.

Araki, A.S., Vigoder, F.M., Bauzer, L.G.S.R., Ferreira, G.E., Souza, N.A., Araújo, I.B., Hamilton, J.G.C., Brazil, R.P., \& Peixoto, A.A. 2009. Molecular and behavioral differentiation among Brazilian populations of Lutzomyia longipalpis (Diptera: Psychodidae: Phlebotominae). PLoS Neglected Tropical Diseases, 3(1): e365.

Arbuckle, T. 2002. Automatic identification of bees' species from images of their wings. In Proc. 9th, International Workshop on Systems, Signals and Image Processing. Manchester, UMIST: pág, 509511.

Arbuckle, B., Schroeder, S., Steinhage, V. \& Wittmann, D. 2001. Biodiversity informatics in action: identification and monitoring of bee species using ABIS. Proc. 15th Conference: International Symposium Informatics for Environmental Protection, Zurich, pág. 425-430.

Arrivillaga, J.C., Norris, D.E., Feliciangeli, M.D. \& Lanzaro, G.C. 2002. Phylogeography of the neotropical sand fly Lutzomyia longipalpis inferred from mitochondrial DNA sequences. Infection, Genetics and Evolution: Journal of Molecular Epidemiology and Evolutionary Genetics in Infectious Diseases, 2(2): 83-95.

Aytekin, A.M., Alten, B., Caglar, S.S., Ozbel, Y., Kaynas, S., Simsek, F.M., Kasap, O.E., Belen, A. 2007. Phenotypic variation among local populations of phlebotomine sandflies (Diptera: Psychodidae) in southern Turkey. Journal of Vector Ecology, 32(2): 226-234. 
Azevedo, A.C., Monteiro, F.A., Cabello, P.H., Souza, N.A., Rosa-Freitas, M.G. \& Rangel, E.F. 2000. Studies on populations of Lutzomyia longipalpis (Lutz \& Neiva, 1912) (Diptera: Psychodidae: Phlebotominae) in Brazil. Memórias do Instituto Oswaldo Cruz, 95(3): 305-322.

Balbino, V.Q., Coutinho-Abreu, I.V., Sonoda, I.V., Melo, M.A., Andrade, P.P., Castro, J.A.F., Rebêlo, J.M., Carvalho, S.M.S. \& Ramalho-Ortigão, M. 2006. Genetic structure of natural populations of the sand fly Lutzomyia longipalpis (Diptera: Psychodidae) from the Brazilian northeastern region. Acta Tropica, 98(1): 15-24.

Bates, P.A., Depaquit, J., Galati, E.A.B, Kamhawi, S., Maroli, M., McDowell, M.A., Picado, A., Ready, P.D., Salomón, O.D., Shaw, J.J., Traub-Csekö, Y.M. \& Warburg, A. 2015. Recent advances in phlebotomine sand fly research related to leishmaniasis control. Parasites \& Vectors, 8:131.

Bauzer, L.G.S.R., Souza, N.A., Maingon, R.D.C. \& Peixoto, A.A. 2007. Lutzomyia longipalpis in Brazil: a complex or a single species? A mini-review. Memórias do Instituto Oswaldo Cruz, 102(1): $1-12$

Bauzer, L.G.R.S., Souza, N.A., Ward, R.D. \& Peixoto, A.A. 2002. The period gene and genetic diferentiation between three brazilian populations of Lutzomyia longipalpis. Insect Molecular Biology, 11(4): 315-323.

Baylac, M., Villemant, C. \& Simbolotti, G. 2003. Combining geometric morphometrics with pattern recognition for the investigation of species complexes. Biological Journal of the Linnean Society, 80(1): 89-98.

Birdsall, K., Zimmerman, E., Teeter, K. \& Gibson, G. 2000. Genetic variation for the positioning of wing veins in Drosophila melanogaster. Evolution \& Development, 2(1): 16-24.

Bottecchia, M., Oliveira, S.G., Bauzer, L.G.R.S, Souza, N.A., Ward, R.D., Garner, K.J., Kyriacou, C.P. \& Peixoto, A.A. 2004. Genetic divergence in the cacophony IVS6 intron among five Brazilian populations of Lutzomyia longipalpis. Journal of Molecular Evolution, 58(6): 754-761.

Brasil. 2006. Ministério da Saúde. Secretaria de Vigilância em Saúde. Departamento de Vigilância Epidemiológica. Manual de Vigilância e Controle da Leishmaniose Visceral - 1. ed. - Brasília: Editora do Ministério da Saúde. 
Brasil. 2007. Ministério da Saúde. Secretaria de Vigilância em Saúde. Departamento de Vigilância Epidemiológica. Manual de Vigilância da Leishmaniose Tegumentar Americana - 2. ed. - Brasília: Editora do Ministério da Saúde.

Brasil. 2016a. Ministério da Saúde. Secretaria de Vigilância em Saúde. Leishmaniose Visceral. Disponível em: <http://portalsaude.saude.gov.br/index.php/o-ministerio/principal/secretarias/svs/ leishmaniose-visceral-lv>. Acesso em: 26 de junho de 2016.

Brasil. 2016b. Ministério da Saúde. Secretaria de Vigilância em Saúde. Leishmaniose Tegumentar Americana. Disponível em: <http://portalsaude.saude.gov.br/index.php/o-ministerio/principal/ secretarias/svs/ leishmaniose-tegumentar-americana-lta>. Acesso em 26 de junho de 2016.

Brazil, R.P. \& Brazil, B.G. 2003. Biologia de flebotomíneos neotropicais. In, Rangel, E. F. \& Lainson, R. Flebotomíneos do Brasil. Rio de Janeiro: Ed. FIOCRUZ, pág. 257-274.

Brazil, R.P. \& Hamilton, J.G. 2002. Isolation and Identification of 9-methylgermacrene-B as the putative sex pheromone of Lutzomyia cruzi (Mangabeira,1938) (Diptera: Psychodidae). Memórias do Instituto Oswaldo Cruz, 97(3): 435-436.

Calle, D.A., Quiñones, M.L., Erazo, H.F. \& Jaramillo, N. 2008. Discriminación por morfometría geométrica de once espécies de Anopheles (Nyssorhynchus) presentes em Colombia. Revista Biomédica, 28(3): 371-385.

Carvalho, M.R., Valença, H.F., da Silva, F.J., de Pita-Pereira, D., de Araújo Pereira, T., Britto, C., Brasil, R.P. \& Brandão Filho, S.P. 2010. Natural Leishmania infantum infection in Migonemyia migonei (França, 1920) (Diptera: Psychodidae: Phlebotominae) the putative vector of visceral leishmaniasis in Pernambuco State, Brazil. Acta Tropica, 116(1): 108-110.

Cazorla, D. \& Acosta, M. 2003. Multivariate morphometric discrimination among three species of Lutzomyia subgenus Micropygomyia (Diptera: Psychodidae). Journal of Medical Entomology, 40(6): 750-754.

Cazorla, D. 2009. Multivariate morphometric differentiation between females of two cryptic species of Lutzomyia subgenus Helcocyrtomyia (Diptera: Psychodidae). Revista Colombiana de Entomologia, 35(2): 197-201.

Coquillett, D.W. 1907. Discovery of blood sucking Psychodidae in America. Entomological News, 18: 101-102. 
De la Riva, J., Le Pont, F., Ali, V., Matias, A., Mollinedo, S. \& Dujardin, J.P. 2001. Wing geometry as a tool for studying the Lutzomyia longipalpis (Diptera: Psychodidae) complex. Memórias do Instituto Oswaldo Cruz, 96(8): 1089-1094.

Demari-Silva, B., Suesdek, L., Sallum, M.A.M. \& Marrelli, M.T. 2014. Wing geometry of Culex coronator (Diptera: Culicidae) from South and Southeast Brazil. Parasites \& Vectors, 7(1): 174.

Devicari, M., Lopes, A.R. \& Suesdek, R. 2011. Dimorfismo sexual alar em Aedes scapularis (Diptera: Culicidae). Biota Neotropica, 11(2): 165-169.

Dujardin, J.P. 2008. Morphometrics applied to medical entomology. Infection, Genetics and Evolution: Journal of Molecular Epidemiology and Evolutionary Genetics in Infectious Diseases, 8(6): 875-890.

Dujardin, J.P, Bermudez, H., Casini, C. \& Tibayrenc, M. 1997a. Metric differences between silvatic and domestic Triatoma infestans (Heteroptera: Reduviidae) in Bolivia. Journal of Medical Entomology, 34(5): 544-551.

Dujardin, J.P., Kaba, D., Solano, P., Dupraz, M., McCoy, K.D. \& Jaramillo-O, N. 2014. Outline-based morphometrics, an overlooked method in arthropod studies? Infections, Genetics and Evolution, 28: 704-714.

Dujardin J.P. \& Le Pont, F. 2000. Morphometrics of a neotropical sandfly subspecies, Lutzomyia carrerai thula. Comptes Rendus de I'Académie des Sciences de Paris. Serie 3: Sciences de la Vie, 323(3): 273-279.

Dujardin, J. \& Le Pont, F. 2004. Geographic variation of metric properties within the neotropical sandflies. Infection Genetics and Evolution, 4(4): 353- 359.

Dujardin, J.P., Le Pont, F. \& Galati, E.A.B. 1999a. Cryptic speciation suspected by morphometry within Lutzomyia runoides. Comptes Rendus de I'Académie des Sciences de Paris. Serie 3: Sciences de la Vie, 322(5): 375-382.

Dujardin, J., Le Pont, F. \& Martínez, E. 1999b. Quantitative morphological evidence for incipient species within Lutzomyia quinquefer (Diptera: Psychodidae). Memorias do Instituto Oswaldo Cruz, 94(6): 829-836.

Dujardin, J.P., Le Pont, F., Matias, A. \& De La Riva, J. 2005. Morphometrical evidence for speciation within Bolivian Lutzomyia aragaoi (Diptera: Psychodidae). Infection, Genetics and Evolution: 
Journal of Molecular Epidemiology and Evolutionary Genetics in Infectious Diseases, 5(4): 362365.

Dujardin, J.P. \& Slice, D.E. 2007. Contributions of Morphometrics to Medical Entomology. In, Tibayrenc, M. Encyclopedia of Infectious Diseases: Modern Methodologies. Ed. John Wiley \& Sons, Inc., pág. 435-447.

Dujardin, J.P., Steindel, M., Chavez, T., Machane, M. \& Schofield, C.J. 1999c. Changes in the sexual dimorphism of Triatominae in the transition from natural to artificial habitats. Memórias do Instituto Oswaldo Cruz, 94(4): 565-569.

Dujardin, J.P., Torrez, E.M., Le Pont, F. \& Hervas, D. 1997b. Isozymic and metric variation in the Lutzomyia longipalpis complex. Medical and Veterinary Entomology, 11(4): 394-400.

Florin, D.A., Davies, S.J., Olsen, C., Lawyer, P., Lipnick, R., Schultz, G., Rowton, E., Wilkerson, R. \& Keep, L. 2011. Morphometric and molecular analyses of the sand fly species Lutzomyia shannoni (Diptera: Psychodidae: Phlebotominae) collected from seven different geographical areas in the Southeastern United States. Journal of Medical Entomology, 48(2): 154-166.

Forattini, O.P. 1973. Entomologia Médica. São Paulo: Ed. Edgard Blucher \& Ed. USP.

Francoy, T.M. \& Imperatriz-Fonseca, V.L. 2010. A morfometria geométrica de asas e a identificação automática de espécies de abelhas. Oecologia Australis, 14(1): 317-321.

Galati, E.A.B, Nunes, V.L., Rego-Jr, F.A, Oshiro, E.T. \& Rodrigues, M. 1997. Estudo de flebotomíneos (Diptera, Psychodidae) em foco de leishmaniose visceral no Estado de Mato Grosso do Sul, Brasil. Revista de Saúde Pública, 31(4): 378-390.

Galati, E.A.B. 2003. Classificação de Phlebotominae e Morfologia, terminologia de adultos e identificação dos táxons da América. In, Rangel, E.F. \& Lainson, R. Flebotomíneos do Brasil. Rio de Janeiro: Ed. FIOCRUZ, pág. 23-51.

Galati, E.A.B. 2014. Classificação de Phlebotominae e Morfologia, terminologia de adultos e identificação dos táxons da América (apostila de atualização desses capítulos do livro). In, Rangel, E.F.; Lainson, R. Flebotomíneos do Brasil, Rio de Janeiro: Ed. FIOCRUZ.

Galati, E.A.B. 1995. Phylogenetic systematics of Phlebotominae (Diptera, Psychodidae) with emphasis on American groups. Boletín de la Dirección de Malariología y Saneamiento Ambiental, 35(1): 133-142. 
Gebre-Michael, T., Lane, R.P. 1993. Distinguishing the females of Phlebotomus (Synphlebotomus) martini and $P$. (S.) celiae (Diptera: Phlebotominae), vectors of visceral leishmaniasis in Southern Ethiopia. Bulletin of Entomological Research, 83(3): 353-360.

Gebre-Michael, T., Medhin, G. 1997. Morphometric separation of females of Phlebotomus (Phlebotomus) duboscqi and P. (P.) bergeroti (Diptera: Psychodidae), Journal of Medical Entomology, 34(4): 383-386.

Godoy, R., Galati, E., Cordeiro-Estrela, P., De Souza, N.A, Dos Santos, T.V., De Sousa, L.C. \& Rangel, E.F. 2014. Comparative study of the phlebotomine sand fly species (Diptera: Psychodidae: Phlebotominae) of the genera Nyssomyia Barretto, 1962, Bichromomyia Artemiev, 1991 and Migonemyia Galati, 1995 vectors of American cutaneous leishmaniasis in Brazil. Zootaxa, 3838(5): 501-517.

Gontijo, C.M.F. \& Melo, M.N. 2004. Leishmaniose Visceral no Brasil: quadro atual, desafios e perspectivas. Revista Brasileira de Epidemiologia, 7(3): 338-349.

Gurgel-Gonçalves, R., Abad-Franch, F., Ferreira, J.B., Santana, D.B. \& Cuba, C.A. 2008. Is Rhodnius prolixus (Triatominae) invading houses in central Brazil? Acta Tropica, 107(2): 90-98.

Gurgel-Gonçalves, R., Maeda, M.H., Ferreira, J.B.C., Rosa, A.F. \& Cuba, C.A.C. 2011. Morphometric changes of Rhodnius neglectus (Hemiptera: Reduviidae) in the transition from sylvatic to laboratory conditions. Zoologia (Curitiba), 28(5): 680-682.

Hamilton, J.G., Maingon R.D., Alexander, B., Ward, R.D. \& Brazil, R.P. 2005. Analysis of the sex pheromone extract of individual male Lutzomyia longipalpis sand flies from six regions in Brazil. Medical and Veterinary Entomology, 19(4): 480-488.

Jirakanjanakit, N. \& Dujardin, J.P. 2005. Discrimination of Aedes aegypti (diptera; culicidae) laboratory lines based on wing geometry. The Southeast Asian Journal of Tropical Medicine and Public Health, 36(4): 858-861.

Jirakanjanakit, N., Leemingsawat, S., Thongrungkiat, S., Apiwathnasorn, C., Singhaniyom, S., Bellec, C. \& Dujardin, J.P. 2007. Influence of larval density or food variation on the geometry of the wing of Aedes (Stegomyia) aegypti. Tropical Medicine and International Health, 12(11): 1354-1360.

Kang, S.H., Jeon, W. \& Lee, S.H. 2012a. Butterfly species identification by branch length similarity entropy. Journal of Asia-Pacific Entomology, 15(3): 437-441. 
Kang, S.H., Song, S.H. \& Lee, S.H. 2012b. Identification of butterfly species with a single neural network system. Journal of Asia-Pacific Entomology 15(3): 431-435.

Killick-Kendrick, R. 1999. The biology and control of phlebotomine sand flies. Clinics in Dermatology, 17(3): 279-89.

Killick-Kendrick, R. 2003. Prefácio. In, Rangel, E.F. \& Lainson, R. Flebotomíneos do Brasil. Rio de Janeiro: Ed. FIOCRUZ, pág. 11-12.

Killick-Kendrick, R., Wilkes, T.J., Bailly, M., Bailly, I. \& Righton, L.A. 1986. Preliminary field observations on the flight speed of a phlebotomine sandfly. Transactions of the Royal Society of Tropical Medicine and Hygiene, 80(1): 138-142.

Klingenberg, C.P. 2011. MorphoJ: an integrated software package for geometric morphometrics. Molecular Ecology Resources, 11(2): 353-357.

Klingenberg, C.P. \& Gidaszewski, N.A. 2010. Testing and quantifying phylogenetic signals and homoplasy in morphometric data. Systematic Biology, 59(3): 245-261.

Lainson, R. \& Rangel, E.F. 2005. Lutzomyia longipalpis and the eco-epidemiology of American visceral leishmaniasis, with particular reference to Brazil. Memórias do Instituto Oswaldo Cruz, 100(8): 811-827.

Landis, J.R. \& Koch, G.G. 1977, The Measurement of Observer Agreement for Categorical Data. Biometrics, 33(1): 159-174.

Lane, R.P. \& Ready, P.D. 1985. Multivariate discrimination between Lutzomyia wellcomei, a vector of mucocutaneous leishmaniasis, and Lu. complexus (Diptera: Phlebotominae). Annals of Tropical Medicine and Parasitology, 79(4): 469-472.

Lanzaro, G.C., Ostrovska, K., Herrero, M.V., Lawyer, P.G. \& Warburg, A. 1993. Lutzomyia longipalpis is a species complex: genetic divergence and interspecific hybrid sterility among three populations. The American Journal of Tropical Medicine and Hygiene, 48(6): 839-847.

Lebbe, J., Torrez, M.E., Vignes, R. \& Dedet, J.P. 1991. Wing morphology and species characterisation of sandflies. Parassitologia, 33: 365-372. 
Lins, R.M.M.A., Souza, N.A., Brazil, R.P., Maingon, R.D.C. \& Peixoto, A.A. 2012. Fixed differences in the paralytic gene define two lineages within the Lutzomyia longipalpis complex producing different types of courtship songs, PLoS ONE 7(9): e44323.

Lorenz, C., Ferraudo, A.S. \& Suesdek, L. 2015. Artificial Neural Network applied as a methodology of mosquito species identification. Acta Tropica, 152: 165-169.

Lorenz, C., Marques, T.C., Sallum, M.A., Suesdek, L. 2012. Morphometrical diagnosis of the malaria vectors Anopheles cruzi, An. homunculus and An. bellator. Parasites \& Vectors, 5(1): 257.

Lyra, M.L., Hatadani, L.M., Azeredo-espin, A.M.L. \& Klaczko, L.B. 2010. Wing morphometry as a tool for correct identification of primary and secondary New World screwworm fly. Bulletin of Entomological Research, 100(1): 19-26.

Madeira, M.F., Uchoa, C.M.A., Leal, C.A., Silva, R.M.M., Duarte, R., Magalhães, C.M. \& Serra, C.M.B. 2003. Leishmania (Viannia) braziliensis em cães naturalmente infectados. Revista da Sociedade Brasileira de Medicina Tropical, 36(5): 551-555.

Maingon, R.D.C., Ward, R.D., Hamilton, J.G.C., Noyes, H.A., Souza, N., Kemp, S.J. \& and Watts, P.C. 2003. Genetic identification of two sibling species of Lutzomyia longipalpis (Diptera: Psychodidae) that produce distinct male sex pheromones in Sobral, Ceará State, Brazil. Molecular Ecology, 12(7): 1879-1894.

Mangabeira, O. 1969. Sobre a sistemática e biologia dos flebotomus do Ceará. Revista Brasileira de Malariologia e Doenças Tropicais, 21: 3-26.

Mayo, M. \& Watson, A.T. 2007. Automatic species identification of live moths. Knowledge-Based Systems, 20(2): 195-202.

Monteiro, L.R. \& Reis S.F. 1999. Princípios de morfometria geométrica, São Paulo: Ed. Holos, 189 págs.

Moraes, E.M., Manfrin, M.H., Laus, A.C., Rosada, R.S., Bomfin, S.C. \& Sene, F.M. 2004. Wing shape heritability and morphological divergence of the sibling species Drosophila mercatorum and Drosophila paranaensis. Heredity, 92(5): 466-473.

Mukhopadhyay, J., Ghosh, K., Azevedo, A.C.R., Rangel, E.F. \& Munstermann, L.E. 1998. Genetic polymorphism in morphological and biochemical characters of Brazilian Lutzomyia longipalpis (Diptera: Psychodidae). Journal of the American Mosquito Control Association, 14(3): 277-282. 
Muñoz-Muñoz, F., Talavera, S. \& Pagès, N. 2011. Geometric morphometrics of the wing in the subgenus Culicoides (Diptera: Ceratoponidae): from practical implications to evolutionary interpretations. Journal of Medical Entomology, 48(2): 129-139.

Murray, H.W., Berman, J.D., Davies, C.R. \& Saravia, N.G. 2005. Advances in leishmaniasis. Lancet, 366(9496): 1561-1577.

Mutebi, J.P., Alexander, B., Sherlock, I., Wellington, J., Souza, A.A., Shaw, J., Rangel, E.F. \& Lanzaro, G.C. 1999. Breeding structure of the sand fly Lutzomyia longipalpis (Lutz \& Neiva) in Brazil. The American Journal of Tropical Medicine and Hygiene, 61(1): 149-157.

Mutebi, J.P., Rowton, E., Herrero, M.V., Ponce, C., Belli, A., Valle, S. \& Lanzaro, G.C. 1998. Genetic variability among populations of the sand fly Lutzomyia (Lutzomyia) longipalpis (Diptera: Psychodidae) from Central America. Journal of Medical Entomology, 35(2): 169-174.

Pessoa, F.A.C., Medeiros, J.F., \& Barrett, T.V. 2007. Effects of timber harvest on phlebotomine sand flies (Diptera: Psychodidae) in a production forest: abundance of species on tree trunks and prevalence of trypanosomatids. Memórias do Instituto Oswaldo Cruz, 102(5): 593-599.

Pimenta, P.F., Secundino, N.F.C. \& Blanco, E.E.N. 2003. Interação Leishmania-hospedeiro invertebrado. In, Rangel, E. F.; Lainson, R. Flebotomíneos do Brasil, Rio de Janeiro: Ed. FIOCRUZ, pág. 275-289.

Pinto, I.S., Andrade Filho, J.D., Santos, C.B., Falqueto, A. \& Leite, Y.L.R. 2010. Phylogenetic relationships among species of Lutzomyia, subgenus Lutzomyia (Diptera: Psychodidae). Journal of Medical Entomology, 47(1): 16-21.

Pinto, I.S., das Chagas, B.D., Rodrigues, A.A.F., Ferreira, A.L., Rezende, H.R., Bruno, R.V., Falqueto, A., Andadre-Filho, J.D., Galati, E.A.B, Shimabukuro, P.H.F., Brazil, R.P. \& Peixoto, A.A. 2015. DNA Barcoding of Neotropical Sand Flies (Diptera, Psychodidae, Phlebotominae): Species Identification and Discovery within Brazil. PLoS ONE, 10(10): e0140636.

Pita-Pereira, D., Cardoso, M.A.B, Alves, C.R., Brazil, R.P. \& Britto, C. 2008. Detection of natural infection in Lutzomyia cruzi and Lutzomyia forattinii (Diptera: Psychodidae: Phlebotominae) by Leishmania infantum chagasi in an endemic area of visceral leishmaniasis in Brazil using a PCR multiplex assay. Acta Tropica, 107(1): 66-69. 
Prudhomme, J., Gunay, F., Rahola, N., Ouanaimi, F., Guernaoui, S., Boumezzough, A., Bañuls, A.L., Sereno, D. \& Alten, B. 2012. Wing size and shape variation of Phlebotomus papatasi (Diptera: Psychodidae) populations from the south and north slopes of the Atlas Mountains in Morocco. Journal of Vector Ecology: Journal of the Society for Vector Ecology, 37(1): 137-147.

Queiroz, M.F.M., Varjão, J.R., Moraes, S.C. \& Salcedo, G.E. 2012. Analysis of sandflies (Diptera: Psychodidae) in Barra do Garças, state of Mato Grosso, Brazil, and the influence of environmental variables on the vector density of Lutzomyia longipalpis (Lutz \& Neiva, 1912). Revista da Sociedade Brasileira de Medicina Tropical, 45(3): 313-317.

Rangel, E.F. \& Lainson, R. 2003. Ecologia das Leishmanioses. In, Rangel, E.F. \& Lainson, R. Flebotomíneos do Brasil, Rio de Janeiro: Ed. FIOCRUZ, pág. 291-310.

Rangel, E.F. \& Lainson, R. 2009. Proven and putative vectors of American cutaneous leishmaniasis in Brazil: aspects of their biology and vectorial competence. Memórias do Instituto Oswaldo Cruz, 104(7): 937-54.

Ready, P.D. 2013. Biology of phlebotomine sand flies as vectors of disease agents. Annual Review of Entomology, 58(1): 227-250.

Rispail, P. \& Léger, N. 1998. Numerical Taxonomy of Old World Phlebotominae (Diptera: Psychodidae): 2. Restatement of Classification upon Subgeneric Morphological Characters. Memórias do Instituto Oswaldo Cruz, 93(6): 787-93.

Rocha, L.S., Santos C.B., Falqueto A., Grimaldi Jr G. \& Cupolillo E. 2010. Molecular biological identification of monoxenous trypanosomatids and Leishmania from antropophilic sand flies (Diptera: Psychodidae) in Southeast Brazil. Parasitology Research, 107(2): 465-468.

Rohlf, F.J. 1996. Morphometric spaces, shape components and the effects of linear transformations. In: Marcus, L.F., Corti, M., Loy, A., Naylor, G.J.P. \& Slice, D. Advances in morphometrics. New York: Ed. Plenum Publication, pág. 117-129.

Rohlf, F.J. 2013. TPSUTIL, version 1.60. Department of Ecology and Evolution, State University of New York, Stony Brook, NY <http://life.bio.sunysb.edu/morph/>. Acesso em: 18 de abril de 2016.

Rohlf, F.J. 2015a. TPSDIG2, version 2.19. Department of Ecology and Evolution, State University of New York, Stony Brook, NY <http://life.bio.sunysb.edu/morph/>. Acesso em: 18 de abril de 2016. 
Rohlf, F.J. 2015b. TPSRELW, version 1.5964 bits. Department of Ecology and Evolution, State University of New York, Stony Brook, NY <http://life.bio.sunysb.edu/morph/>. Acesso em: 18 de abril de 2016.

Rohlf, F.J. \& Marcus, L.F. 1993. A Revolution in Morphometrics. Trends in Ecology \& Evolution, 8(4): 129-132.

Romero, G.A. \& Boelaert, M. 2010. Control of visceral leishmaniasis in Latin America - A systematic review. PLoS Neglected Tropical Diseases, 4(1): e584.

Santos, S.O., Arias, J., Ribeiro, A.A., de Paiva Hoffmann, M., de Freitas R.A. \& Malacco, M.A. 1998. Incrimination of Lutzomyia cruzi as a vector of American visceral leishmaniasis. Medical and Veterinary Entomology, 12(3): 315-317.

Santos, M.F., Andrade Filho, J.D., Fernandes, C.E., Mateus, N.L., Eguchi, G.U., Fernandes, W.D., Brazil, R.P., Oliveira, E.F. \& Oliveira, A.G. 2015. Morphometric Analysis of Longipalpis (Diptera: Psychodidae) Complex Populations in Mato Grosso do Sul, Brazil. Journal of Medical Entomology, 52(3): 359-67.

Santos, M.F., Ribolla, P.E.M., Alonso, D.P., Andrade-Filho, J.D., Casaril, A.E., Ferreira, A.M.T., Fernandes, C.E.S., Brazil, R.P. \& Oliveira, A.G. 2013. Genetic structure of Lutzomyia longipalpis populations in Mato Grosso do Sul, Brazil, based on microsatellite markers. PLoS ONE, 8(9): e74268.

Shaw J., Rosa A.T., Souza A. \& Cruz A.C. 2003. Transmissão de outros agentes. In, Rangel, E.F. \& Lainson, R. Flebotomíneos do Brasil, Rio de Janeiro: Ed. FIOCRUZ, pág. 337-351.

Sherlock, I.A. 2003. Importância Médico-Veterinária. In, Rangel, E.F. \& Lainson, R. Flebotomíneos do Brasil, Rio de Janeiro: Ed. FIOCRUZ, pág. 15-22.

Shimabukuro, P.H., Carvalho, G.M.L., Gontijo, C.M.F. \& Rêgo, F.D. 2016. Description of the Female of Martinsmyia minasensis (Diptera, Psychodidae, Phlebotominae), With Distribution Records and a Key to Female Identification. Journal of Medical Entomology, 53 (3): 533-540

Silva, A.M., Camargo, N. J., Santos, D.R., Massafera, R., Ferreira, A.C., Postai, C., Cristóvão, E.C., Konolsaisen, J.F., Bisetto Júnior, A., Perinazo, R., Teodoro, U. \& Galati, E.A.B. 2008. Diversidade, distribuição e abundância de flebotomíneos (Diptera: Psychodidae) no Paraná. Neotropical Entomology, 37(2): 209-225. 
Smith, H., Mullens, B.A. 2003. Seasonal activity, size, and parity of Culicoides occidentalis (Diptera: Ceratopogonidae) in a coastal southern California salt marsh. Journal of Medical Entomology, 40(3): 352-355.

Soares, R.P.P. \& Santoro, M.M. 2000. a-Glycerophophate dehydrogenase activity in flight muscles of triatomine bugs Panstrongylus megistus and Triatoma sordida. Memórias do Instituto Oswaldo Cruz, 95(5): 707-709.

Souza, N.A., Vigoder, F.M., Araki, A.S., Ward, R.D., Kyriacou, C.P. \& Peixoto, A.A. 2004. Analysis of the copulatory courtship songs of Lutzomyia longipalpis in six populations from Brazil. Journal of Medical Entomology, 41(5): 906-913.

StatSoft, Inc. 2011. STATISTICA, version 10. Tulsa, USA, data analysis software system. <http://www.statsoft.com>. Acesso em: 18 de abril de 2016.

Vidal, P.O., Carvalho, E. \& Suesdek, L. 2012. Temporal variation on wing geometry of Aedes albopictus. Memórias do Instituto Oswaldo Cruz, 107(8): 1030-1034.

Vidal, P.O., Peruzin, M.C. \& Suesdek, L. 2011. Wing diagnostic characters for Culex quinquefasciatus and Culex nigripalpus (Diptera: Culicidae). Revista Brasileira de Entomologia, 55(1): 134-137.

Vigoder, F.M., Araki, A.S., Bauzer, L.G.S.R., Souza, N.A., Brazil, R.P. \& Peixoto, A.A. 2010. Lovesongs and period gene polymorphisms indicate Lutzomyia cruzi (Mangabeira, 1938) as a sibling species of the Lutzomyia longipalpis (Lutz and Neiva, 1912) complex. Infection, Genetics and Evolution: Journal of Molecular Epidemiology and Evolutionary Genetics in Infectious Diseases, 10(6): 734-739.

Virgninio, F. \& Suesdek, L. 2016. WingBank: a mosquito wing image database. Abstracts of IV International Meeting in Infectious Disease Research and Tropical Medicine, Pontifical Catholic University of Ecuador (PUCE) Quito, Ecuador.

Wang, J., Ji, L., Liang, A. \& Yuan, D. 2012. The identification of butterfly families using contentbased image retrieval. Biosystems Engineering, 111(1): 24-32.

Ward, R.D., Ribeiro, A.L., Ready, P.D. \& and Murtagh, A. 1983. Reproductive isolation between different forms of Lutzomyia longipalpis (Lutz \& Neiva) (Diptera: Psychodidae), the vector of Leishmania donovani chagasi Cunha \& Chagas and its significance to kala-azar distribution in South America. Memórias do Instituto Oswaldo Cruz, 78(3): 269-280. 
Ward, R. D., Ribeiro, A. L., Ryan, L., Falcão, A. L., \& Rangel, E. F. 1985. The distribution of two morphological forms of Lutzomyia longipalpis (Lutz \& Neiva) (Diptera: Psychodidae). Memórias do Instituto Oswaldo Cruz, 80(2): 145-148.

World Health Organization (WHO). 2010a. Control of the leishmaniases: report of a meeting of the WHO Expert Committee on the Control of Leishmaniases, Geneva, 22-26 March 2010. WHO Technical Report Series No 949.

World Health Organization (WHO). 2010b. First WHO report on neglected tropical diseases: working to overcome the global impact of neglected tropical diseases.

Yang, H.P., Ma, C.S., Wen, H., Zhan, Q.B. \& Wang, X.L. 2015. A tool for developing an automatic insect identification system based on wing outlines. Scientific Reports, 5:12786.

Yin, H., Mutebi, J.P., Marriott, S. \& Lanzaro, G.C. 1999. Metaphase karyotypes and G-banding in sandflies of the Lutzomyia longipalpis complex. Medical and Veterinary Entomology, 13(1): 72-77.

Young, D. G. \& Duncan, M. A. 1994. Guide to the identification and geographic distribution of Lutzomyia sand flies in Mexico, the West Indies, Central and South America (Diptera: Psychodidae). Memoirs of the American Entomological Institute, 54: 1-881.

Young, D.G. \& Perkins, P.V. 1984. Phlebotomine sand flies of North America (Diptera: Psychodidae). Journal of the American Mosquito Control Association, 44(2): 263-304.

Zapata, S., León, R., Sauvage, F., Augot, D., Trueba, G., Cruaud, C., Couloux, A., Terán, R. \& Depaquit, J. 2012. Morphometric and molecular characterization of the series Guyanensis (Diptera, Psychodidae, Psychodopygus) from the Ecuadorian Amazon Basin with description of a new species. Infection, Genetics and Evolution: Journal of Molecular Epidemiology and Evolutionary Genetics in Infectious Diseases, 12(5): 966-977. 


\section{APÊNDICE}

\begin{tabular}{|c|c|}
\hline Espécies & Localidade de Origem \\
\hline Lu. alencari & $\begin{array}{l}\text { Minas Gerais: Itanhomi, Dom Joaquim, Barra Longa, Acaiaca e Jequitinhonha } \\
\text { Espírito Santo: Mimoso, São Francisco, Ecoporanga e Baixo Guandú }\end{array}$ \\
\hline Lu. almerioi & $\begin{array}{l}\text { Mato Grosso do Sul: Guaicurus, Bálsamo do Rio Perdido, Bodoquena, Lago } \\
\text { azul (Bonito), Gruta dos Carneiros (Bonito) e Pitangueira }\end{array}$ \\
\hline Lu. cavernicola & Tocantins: Dianópolis e Januária \\
\hline Lu. cruzi & Mato Grosso do Sul: Corumbá \\
\hline Lu. dispar & $\begin{array}{l}\text { Mato Grosso do Sul: Alcinópolis e Aquidauana } \\
\text { Piauí: Cristovinho }\end{array}$ \\
\hline Lu. forattinii & Mato Grosso do Sul: Corumbá \\
\hline Lu. gaminarai & Paraná: Ribeirão Claro \\
\hline Lu. longipalpis & Mato Grosso do Sul: Bodoquena \\
\hline Lu. ischnacantha & Minas Gerais: Januária, Pirapora e Montes Claros \\
\hline Lu. ischyracantha & $\begin{array}{l}\text { Minas Gerais: Santa Bárbara, Jaboticatubas, Santana do Riacho, Dom } \\
\text { Joaquim, Diamantina, Conceição do Mato Dentro, Rio Acima e Itambé }\end{array}$ \\
\hline Lu. renei & Minas Gerais: Lagoa Santa e Lassance \\
\hline Lu. lichyi & $\begin{array}{l}\text { Venezuela: Aragua (San Casimiro e Zamora) e Sucre (Montes) } \\
\text { Peru: Huánuco (Província de Leoncio Prado) }\end{array}$ \\
\hline Lu. battistinii & Peru: Ayacucho, Cusco e Huancavelica \\
\hline Lu. ayacuchensis & Peru: Ayacucho e Cajamarca \\
\hline
\end{tabular}

Mi. quinquefer

Minas Gerais: Peçanha, Arinos, Acaiaca, Barra Longa, Itanhomi e Caparaó Piauí: Barro Duro 
Br. brumpti

Br. avellari
Minas Gerais: Divinópolis

Mato Grosso: Denise, Poconé, Chapada dos Guimarães e Alta Floresta

Minas Gerais: Pato de Minas e Tupaciquara

Mato Grosso do Sul: Camapuã e Rio Verde Maranhão: Cururupu 